\title{
Circulating Extracellular Histones Are Clinically Relevant Mediators of Multiple Organ Injury
}

\author{
Chihiro Kawai, Hirokazu Kotani, Masashi Miyao, Tokiko Ishida, Leila Jemail, Hitoshi Abiru, and Keiji Tamaki
}

From the Department of Forensic Medicine, Kyoto University Graduate School of Medicine, Kyoto, Japan

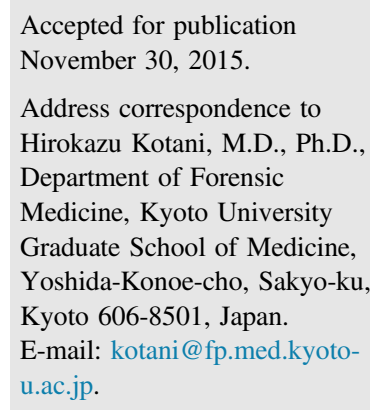

\begin{abstract}
Extracellular histones are a damage-associated molecular pattern (DAMP) involved in the pathogenesis of various diseases. The mechanisms of histone-mediated injury in certain organs have been extensively studied, but an understanding of the pathophysiological role of histone-mediated injury in multiple

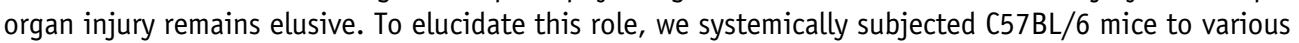
doses of histones and performed a chronological evaluation of the morphological and functional changes in the lungs, liver, and kidneys. Notably, histone administration ultimately led to death after a dosedependent aggravation of multiple organ injury. In chronological studies, pulmonary and hepatic injuries occurred within 15 minutes, whereas renal injuries presented at a later phase, suggesting that susceptibility to extracellular histones varies among organs. Histones bound to pulmonary and hepatic endothelial cells immediately after administration, leading to endothelial damage, which could be ameliorated by pretreatment with heparin. Furthermore, release of another DAMP, high-mobility group protein box 1 , followed the histone-induced tissue damage, and an antibody against the molecule ameliorated hepatic and renal failure in a late phase. These findings indicate that extracellular histones induce multiple organ injury in two progressive stages-direct injury to endothelial cells and the subsequent release of other DAMPs - and that combination therapies against extracellular histones and high-mobility group protein box 1 may be a promising strategy for treating multiple organ injury. (Am J Pathol 2016, 186: 829-843; http://dx.doi.org/10.1016/j.ajpath.2015.11.025)
\end{abstract}

The intracellular contents released from damaged cells-termed damage-associated molecular patterns (DAMPs) - stimulate innate immunity and lead to tissue damage. ${ }^{1,2}$ The pathogenesis of DAMP-induced damage has been extensively studied in certain organs, typically after the injection of a DAMP into a vessel feeding the organ of interest. ${ }^{3,4}$ Those studies have demonstrated that most DAMPs induce damage by linking and activating cellular pattern-recognition receptors, including Toll-like receptors (TLRs) on immune cells. Moreover, they have suggested that DAMPs also can damage remote organs and lead eventually to multiple organ failure (MOF) once released into the blood circulation. ${ }^{5,6}$ However, the pathophysiological mechanisms of DAMP-induced MOF remain unclear. ${ }^{5}$

Histones are major nuclear proteins recently recognized as a member of the DAMP family. ${ }^{2,7,8}$ Since $\mathrm{Xu}$ et al ${ }^{7}$ revealed that extracellular histones contributed to organ failure and death during sepsis, elevated circulating histone levels have been found in seriously ill patients with various internal and external disorders-including cerebrovascular diseases, ischemic heart diseases, autoimmune diseases, and traumas. ${ }^{9-12}$ These findings suggest that circulating histones appear secondary to various disorders and can have causative effects on MOF in patients. Furthermore, recent studies have identified distinct receptor-dependent and receptorindependent mechanisms of extracellular histone toxicity, ${ }^{13}$ which function separately or in collaboration to induce tissue injury. In the receptor-dependent mechanism, histones mainly bind and activate TLRs on various cells, similar to other DAMP molecules, subsequently triggering sterile inflammation and/or platelet aggregation.,14,15 Alternatively, histone-mediated cytotoxicity through receptor-independent means results from their positive charge, which enables their

Supported by departmental funding from Kyoto University Graduate School of Medicine.

Disclosures: None declared. 
direct binding to the negatively charged plasma membrane of target cells. ${ }^{16,17}$ Histone binding disrupts the plasma membrane, thereby causing a calcium influx into the cytoplasm and the induction of cell death. ${ }^{9,18}$ In addition, extracellular histones could elicit coagulopathy-induced MOF via thrombin autoactivation and fibrin formation in the blood plasma. ${ }^{19}$ During this process, histones would likely bind both protein $\mathrm{C}$ and thrombomodulin, resulting in impairing fibrinolysis. ${ }^{20}$ However, no in vivo study thus far has investigated the involvement of these mechanisms in multiple organ injury.

Several potential agents against histone toxicity have been proposed. ${ }^{13} \mathrm{~A}$ histone-neutralizing antibody has been shown to bind all histone subunits and to ameliorate histoneinduced pathology in mouse models of sepsis and trauma. ${ }^{7,8}$ In addition, in vitro histone cytotoxicity was abolished by the presence of various molecules in blood plasma, such as the following: activated protein $\mathrm{C}$, which acts as a serum protease to degrade extracellular histones ${ }^{7}$; and electrically negative-charged agents, including heparin, albumin, pentraxin 3, and C-reactive protein, which can bind histones through a charge interaction to neutralize their positive charge and attenuate histone cytotoxicity. ${ }^{21-24}$ Nonetheless, in vivo confirmation of the functionality of these negatively charged agents is needed to further the development of therapeutic strategies for histone-induced MOF. ${ }^{25}$

Here we performed a chronological evaluation of the morphological and functional changes in the lungs, liver, and kidneys of C57BL/6 mice subjected to various doses of histones to elucidate the role of circulating extracellular histones in inducing multiple organ injury. We also studied the interaction between extracellular histones and the endothelial cells with regard to disease severity and susceptibility to organ injury. Moreover, we investigated the effects of potential agents against histone toxicity in mice.

\section{Materials and Methods}

\section{Animals}

Male C57BL/6 mice ( 8 to 9 weeks old, 20 to $25 \mathrm{~g}$; CLEA Japan Inc., Tokyo, Japan) were used for all experiments. All mice were housed in cages, under specific pathogen-free conditions, in an air-conditioned room at $25^{\circ} \mathrm{C}$ with a 12-hour light/dark cycle and were provided food and water ad libitum. For in vivo model systems, mice were injected i.v. with histones (Sigma-Aldrich, St. Louis, MO) at the indicated dose in a total volume of $100 \mu \mathrm{L}$. Sham mice were injected i.v. with $100 \mu \mathrm{L}$ of saline as a control. Experimental animals were sacrificed at each indicated time point, blood was collected by cardiac puncture, and the serum samples were stored at $-80^{\circ} \mathrm{C}$ until further analyses. For light microscopic and transmission electron microscopic analyses, lungs, liver, and kidneys were harvested and fixed in $4 \%$ buffered formaldehyde or $4 \%$ paraformaldehyde $/ 2 \%$ glutaraldehyde for the respective analyses. All experiments consisted of $\geq 5$ mice per group, unless otherwise indicated.
For survival analysis, mice were injected i.v. with histones $(50,75$, or $100 \mathrm{mg} / \mathrm{kg}$ ) or $100 \mathrm{mg} / \mathrm{kg}$ of boiled histones and were monitored for 64 hours. Mice were euthanized by cervical dislocation on presentation with signs of severe distress, such as dyspnea, cyanosis, or nonresponsiveness to touch, and were recorded as a histoneinduced mortality. For dose-response analysis, mice were injected i.v. with histones $(25,50$, or $75 \mathrm{mg} / \mathrm{kg})$ and sacrificed at 4 hours after administration for the collection of samples for further processing. For time-course analysis, mice were injected i.v. with $75 \mathrm{mg} / \mathrm{kg}$ of histones and sacrificed at 15 minutes or at $1,4,16$, or 64 hours after administration for the collection of samples for further processing.

All experimental protocols were approved by the Animal Care and Use Committee of Kyoto University and were performed according to the criteria outlined in the Guide for the Care and Use of Laboratory Animals (NIH, Bethesda, MD).

\section{Pharmacological Treatments and Compounds}

To assess the effects of heparin or albumin treatment, 10 $\mathrm{mg} / \mathrm{kg}$ of heparin sodium salt (Sigma-Aldrich) or $1 \mathrm{~g} / \mathrm{kg}$ of bovine serum albumin (Sigma-Aldrich) was co-injected i.v. with $100 \mathrm{mg} / \mathrm{kg}$ of histones (for survival rate analyses) or 75 $\mathrm{mg} / \mathrm{kg}$ of histones (for other experiments). For survival rate analysis, mice were monitored for 64 hours; for other experiments, mice were sacrificed at 4 hours after administration for the collection of samples for further processing. In addition, to more practically represent clinical scenarios, $10 \mathrm{mg} / \mathrm{kg}$ of heparin sodium salt or saline was injected i.v. at 15 minutes after the injection of $75 \mathrm{mg} / \mathrm{kg}$ of histone, and mice were monitored for 16 hours for survival analyses or were sacrificed at 4 hours after histone injection for the collection of blood samples. To assess the potential beneficial role of high-mobility group protein box 1 (HMGB1) neutralization in histone-induced multiple organ injuries, mice were injected i.p. with $200 \mathrm{mg} / \mathrm{kg}$ of anti-Hmgb1 antibody (Shino-Test, Tokyo, Japan) at 30 minutes before and at 1 hour after injection with $75 \mathrm{mg} / \mathrm{kg}$ of histones. Control mice were injected i.p. with $\operatorname{IgY}$ fraction (Shino-Test).

\section{Mouse Models of Systemic Injury}

Mouse models of ischemia-reperfusion and toxemia were used in our analyses. For the ischemia-reperfusion model, mice were anesthetized with an i.p. injection of $50 \mathrm{mg} / \mathrm{kg}$ of pentobarbital, and approximately $30 \%$ blood of the total volume $(0.6 \mathrm{~mL} / 25 \mathrm{~g})$ was removed via cardiac puncture with a heparinized syringe. After 1 hour of ischemia, the blood was reperfused into the vein. Sham mice were subjected to the same procedures, without blood withdrawal and resuscitation. ${ }^{26}$ Toxemia was induced with an i.p. injection of $10 \mathrm{mg} / \mathrm{kg}$ of lipopolysaccharide (Sigma-Aldrich) or an i.v. injection of $75 \mathrm{mg} / \mathrm{kg}$ of zymosan (Sigma-Aldrich). ${ }^{27}$ 
Sham mice received an equivalent volume of saline. Mice were sacrificed at 12 hours after reperfusion or lipopolysaccharide injection, or at 15 minutes or 4 hours after zymosan injection. Blood and organs (lungs, liver, and kidneys) were collected for further analyses.

\section{In Vivo Pulmonary Permeability Assays}

Pulmonary microvascular permeability was measured using Evans Blue dye as previously described. ${ }^{28}$ Briefly, $40 \mathrm{mg} / \mathrm{kg}$ of Evans Blue (Sigma-Aldrich) was injected i.v. at 1 hour before histone injections. The lungs were harvested from mice sacrificed at the indicated time points, perfused with phosphate-buffered saline for 1 minute, dried at $60^{\circ} \mathrm{C}$ for 48 hours, and then weighed. The Evans Blue in the dried lungs was extracted by immersion in $3 \mathrm{~mL}$ of $100 \%$ formamide at $37^{\circ} \mathrm{C}$ for 24 hours. The Evans Blue concentration in the supernatant was then determined by absorbance at $620 \mathrm{~nm}$ with a spectrophotometer (Genesys 10S UV-Vis; Thermo Scientific, Waltham, MA) and expressed as $\mu \mathrm{g} / \mathrm{mg}$ of dry tissue weight.

\section{Biochemical Assays}

Serum alanine transaminase, aspartate transaminase, blood urea nitrogen, and creatinine levels were analyzed using a Hitachi 7180 analyzer (Hitachi, Tokyo, Japan). Circulating nucleosomes in the blood plasma were measured using the Cell Death Detection ELISA ${ }^{\text {PLUS }}$ (Roche, Mannheim, Germany). Serum levels of tumor necrosis factor- $\alpha$, Il- $1 \beta$, Il-6, and Il-10 were measured using enzyme-linked immunosorbent assay (ELISA) kits (R\&D Systems, Minneapolis, $\mathrm{MN})$. The serum concentrations of soluble thrombomodulin and Hmgb1 were quantified with ELISA kits purchased from Cusabio Biotech (Wuhan, China) or Shino-Test. Total histones in urine were measured with an ELISA kit purchased from Epigentek Group Inc. (New York, NY).

\section{Histological Examination}

Formalin-fixed, paraffin-embedded tissue samples were sectioned ( $3 \mu \mathrm{m}$ thick), deparaffinized, and stained with hematoxylin and eosin or periodic acid-Schiff. Other harvested samples were immediately frozen in an optimal cutting-temperature compound and stored at $-80^{\circ} \mathrm{C}$ for further analyses. Histological changes in the lungs, livers, and kidneys of experimental animals were evaluated by individual morphological parameters. In the lungs, lung injuries were scored according to a standardized guideline set by the American Thoracic Society, ${ }^{29}$ in which alveolar neutrophils, interstitial neutrophils, hyaline membranes, proteinaceous debris in airspaces, and alveolar septal thickening were individually scored and summed. The degree of liver microscopic injury was quantified by a count of the number of necrotic cells. Histological kidney changes were scored based on polymorphonuclear leukocyte infiltration, proximal tubular cell necrosis, brush border loss, cast formation, and tubular dilatation, which were used for calculating an acute tubular necrosis score as previously described.$^{14}$ In addition, a more detailed assessment of polymorphonuclear leukocyte infiltration in each organ was conducted by a densitometric assessment of neutrophil infiltration in ImageJ software version 1.46 (NIH; http://imagej.nih.gov/ij). Quantification of each parameter was performed in 10 randomly selected areas in each specimen at $400 \times$ magnification. Specimen histological examination was assessed by an experienced pathologist (C.K.) and an attending pathologist (H.K.) in a blinded fashion to obtain a consensus diagnosis for each sample.

\section{Immunohistochemistry Analysis of Formalin-Fixed, Paraffin-Embedded Tissue Samples}

Immunohistochemistry staining of the specimens was performed as previously described. ${ }^{30}$ Briefly, antigen was retrieved in a pressure cooker by boiling in $10 \mathrm{mmol} / \mathrm{L}$ citrate buffer (pH 6.0), followed by washing with phosphate-buffered saline. Subsequently, endogenous peroxidase was quenched with $3 \% \mathrm{H}_{2} \mathrm{O}_{2}$ for 10 minutes at room temperature. After rinsing, the slides were treated overnight at $4^{\circ} \mathrm{C}$ with a negative control reagent or the following primary antibodies: Hmgb1 (rabbit polyclonal, 1:1000; Abcam, Cambridge, MA), histone H3 (rabbit polyclonal, 1:1000; Abcam), and Ki-67 (mouse monoclonal, 1:200; Novocastra Laboratories, New Castle, UK). The slides were then incubated with anti-rabbit or anti-mouse horseradish peroxidase-conjugated secondary antibody (goat polyclonal, prediluted; Medical \& Biological Laboratories Co., Ltd., Nagoya, Japan). Antibody binding was detected with the labeled polymer method. Diaminobenzidine was used as a chromogen, followed by counterstaining with hematoxylin.

\section{Immunofluorescence Analyses of Frozen Tissue Samples}

Immunohistochemistry staining of frozen sections was performed according to the manufacturer's instructions. Briefly, frozen specimens were fixed in $4 \%$ paraformaldehyde for 30 minutes, sectioned ( $6 \mu \mathrm{m}$ thick), blocked with $5 \%$ bovine serum albumin, washed, and incubated with histone $\mathrm{H} 3$ antibody (rabbit polyclonal, 1:1000; Abcam). Subsequently, slides were incubated with Alexa Fluor 488 goat anti-rabbit secondary antibody (Cell Signaling Technology, Beverly, MA), Alexa Fluor 594 phalloidin, and DAPI for nuclear staining (Thermo Scientific).

\section{Transmission Electron Microscopy}

Samples were prepared as previously described. ${ }^{30}$ Briefly, the lungs, livers, and kidneys were fixed in $4 \%$ paraformaldehyde/ $2 \%$ glutaraldehyde and cut into $1-\mathrm{mm}^{3}$ sections. The specimens were extensively washed with phosphate-buffered saline, postfixed in $1 \%$ osmium tetroxide, dehydrated in a graded 
Table 1 RT-PCR Primers for Analysis

\begin{tabular}{|c|c|c|}
\hline \multicolumn{3}{|c|}{ Primer name Direction Sequence } \\
\hline $\operatorname{Tnf}-\alpha$ & Forward & $5^{\prime}$-СССTCACACTCAGATCATCTTCT-3' \\
\hline Tnf- $\alpha$ & Reverse & 5'-GCTACGACGTGGGCTACAG- $3^{\prime}$ \\
\hline Ill $1-\beta$ & Forward & $5^{\prime}$-CCAGCTTCAAATCTCACAGCAG-3' \\
\hline Ill- $\beta$ & Reverse & 5'-СTTCTTTGGGTATTGCTTGGGATC-3' \\
\hline Il-6 & Forward & 5'-TAGTCCTTCCTAССCCAАTTTCC-3' \\
\hline Il-6 & Reverse & 5'-TTGGTCCTTAGCCACTCCTTC-3' \\
\hline Il-10 & Forward & $5^{\prime}-$ TGGCCCAGAAATCAAGGAGC- $3^{\prime}$ \\
\hline Il-10 & Reverse & $5^{\prime}-$ CAGCAGACTCAATACACACT-3' \\
\hline Vegfr2 & Forward & 5'-CCTGGTAGAAGATTCAGGCATTG-3' \\
\hline Vegfr2 & Reverse & $5^{\prime}$-CCTCACCCTGCGGATAGTCA-3' \\
\hline Tlr2 & Forward & $5^{\prime}$-CAGCTGGAGAACTCTGACCC-3' \\
\hline Tlr2 & Reverse & $5^{\prime}$-CAAAGAGCCTGAAGTGGGAG- $3^{\prime}$ \\
\hline Tlr4 & Forward & $5^{\prime}$-CAACATCATCCAGGAAGGC- $3^{\prime}$ \\
\hline Tlr4 & Reverse & 5'-GAAGGCGATACAATTCCACC-3' \\
\hline Gapdh & Forward & 5'-AGGTCGGTGTGAACGGATTTG-3' \\
\hline Gapdh & Reverse & 5'-TGTAGACCATGTAGTTGAGGTCA-3' \\
\hline
\end{tabular}

Gapdh, glyceraldehyde-3-phosphate dehydrogenase; Tlr, Toll-like receptor; Tnf, tumor necrosis factor; Vegfr, vascular endothelial growth factor receptor.

ethanol series, and embedded in Epon (Nacalai Tesque, Kyoto, Japan). Semi-thin sections $(750 \mathrm{~nm})$ were stained with toluidine blue, and ultrathin sections ( $80 \mathrm{~nm}$ ) were stained with $1 \%$ uranyl acetate and with lead citrate as a counterstain and were examined on an H-7650 electron microscope (Hitachi).

\section{Quantitative RT-PCR}

Total RNA was extracted from lung, liver, and kidney tissues with TRIzol (Life Technologies, Carlsbad, CA) and used for synthesizing cDNA in reactions containing $800 \mathrm{ng}$ of total RNA with the SuperScript III First-Strand Synthesis System (Life Technologies). Real-time PCR performed using FastStart Universal SYBR Green Master Mix (Roche) and Rotor-Gene Q (Qiagen, Venlo, the Netherlands). The primer pairs used are provided in Table 1. Each real-time PCR was performed with three individual samples $(n=3)$, and in triplicate. Data analysis was performed using the $2^{-\Delta \Delta \mathrm{C}_{\mathrm{T}}}$ method for relative quantification, with a glyceraldehyde-3-phosphate dehydrogenase internal control.

\section{Turbidity Measurement}

To assess heparin-induced histone aggregation, $1 \mathrm{mg} / \mathrm{mL}$ heparin sodium salt (Sigma-Aldrich) was mixed with histones $(0.125,0.25,0.5,1$, or $2 \mathrm{mg} / \mathrm{mL})$. The turbidity of the mixture was determined by OD at $310 \mathrm{~nm}$ with a spectrophotometer (Thermo Scientific) with three individual samples. ${ }^{23}$

\section{Statistical Analysis}

Data are reported as the arithmetic means \pm SEM. All data were analyzed in IBM SPSS Statistics version 20.0 software
(IBM Corp., Armonk, NY). Statistical significance was determined with Student's $t$-tests or the log-rank test for survival analysis. $P<0.05$ was considered statistically significant.

\section{Results}

\section{Extracellular Histones Mediate a Systemic Response Ultimately Resulting in Death}

Elevations in circulating nucleosomes - an extracellular frame composed of histones and DNA-have been reported in various diseases, including acute ischemia, sepsis, and trauma $^{7-9}$ Thus, we first investigated nucleosome release into the blood circulation in mouse models of ischemia-reperfusion and lipopolysaccharide-induced toxemia, which were significantly increased, by 5 -fold and 40-fold, respectively, compared to those in sham mice (Figure 1A).

To evaluate the systemic effects of extracellular histones in the blood circulation, we performed a survival analysis and a macroscopic analysis of mice injected with increasing doses of histones $(0,50,75$, and $100 \mathrm{mg} / \mathrm{kg})$. Notably, all mice injected with $100 \mathrm{mg} / \mathrm{kg}$ of histones and $25 \%$ of those injected $75 \mathrm{mg} / \mathrm{kg}$ of histones died, half of which died within 15 minutes, whereas sham mice and those injected with $50 \mathrm{mg} / \mathrm{kg}$ of histones survived for 64 hours (Figure 1B). Moreover, the survival rate of mice injected with $100 \mathrm{mg} / \mathrm{kg}$ of boiled histones was significantly higher than that of mice injected with same dose of nonboiled histones (Supplemental Figure S1). In addition, the survival rates of 20-week-old mice were comparable to those of 8- to 9-week-old mice $(100 \mathrm{mg} / \mathrm{kg}$ of histone injection, $P=0.523 ; 75 \mathrm{mg} / \mathrm{kg}$ of histone injection, $P=0.953$ ). Macroscopically, the lungs of mice injected with $100 \mathrm{mg} / \mathrm{kg}$ of histones were visibly enlarged and severely congested (Figure 1C), whereas other organs-including the liver and kidney-did not show apparent gross anatomical changes (data not shown). To evaluate whether the histone-induced organ injuries were accompanied by systemic inflammation, we next examined the serum levels of the pro- and anti-inflammatory cytokines, tumor necrosis factor- $\alpha$, Il- $1 \beta$, Il-6, and Il-10, in mice injected with 25 to $75 \mathrm{mg} / \mathrm{kg}$ of histones at 4 hours after injection. Consequently, the concentrations of all cytokines were increased in a dosedependent manner (ranging from 2- to 200-fold) following injection with histones when compared to concentrations in sham mice (Figure 1D). These results suggest that increases in extracellular histones cause broad and causative influences in the progression of systemic inflammation that may lead to death.

\section{Extracellular Histones Induce Multiple Organ Injury in a Dose-Dependent Manner}

To further assess the detrimental role of extracellular histones in systemic organs, we investigated the histopathological and 


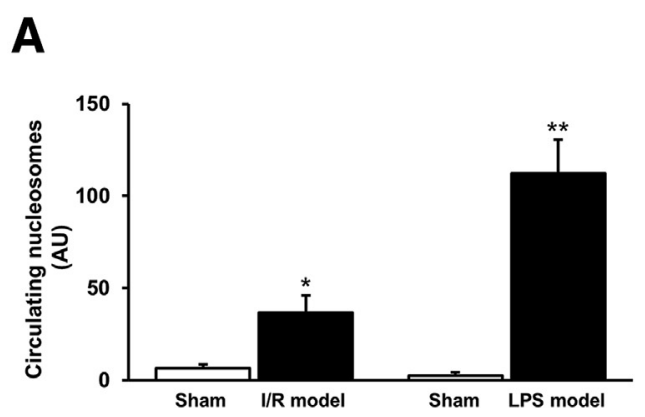

B

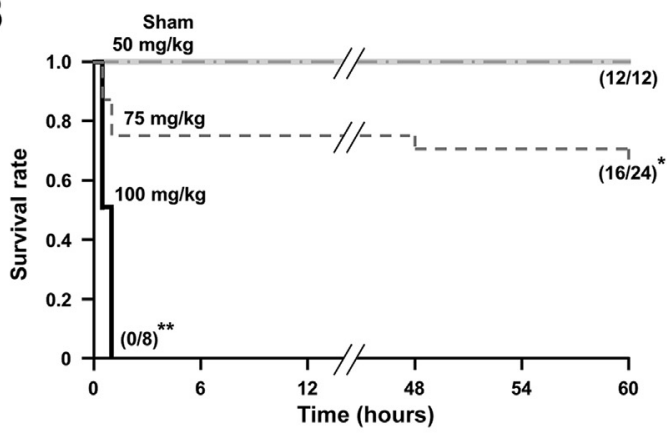

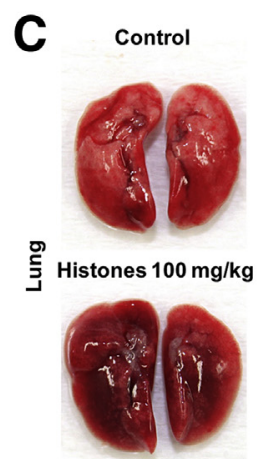

D
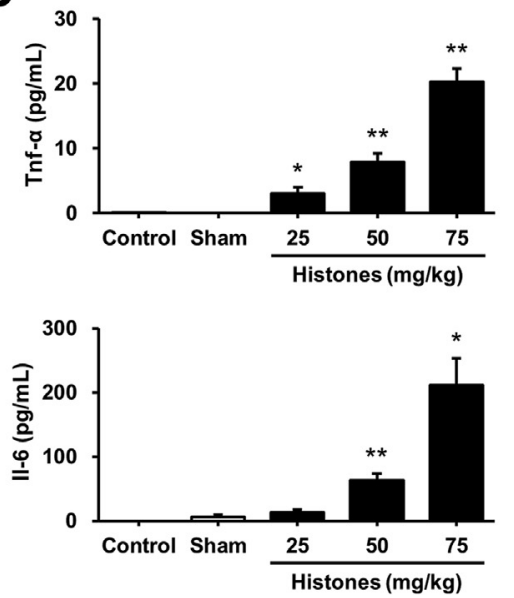
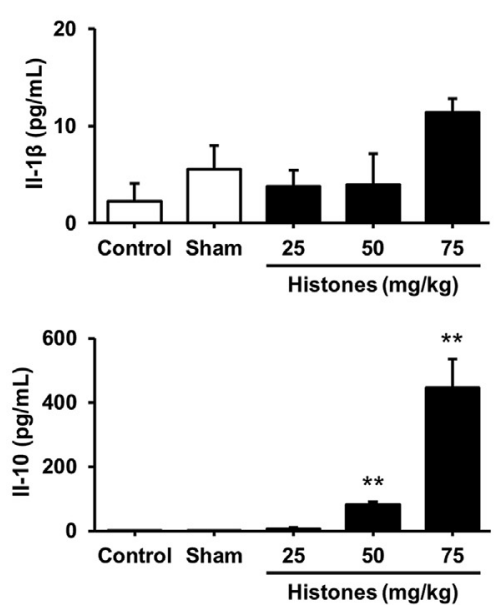

Figure 1 Extracellular histones mediate a systemic response ultimately resulting in death. A: Serum levels of circulating nucleosomes in sham, ischemia-reperfusion (I/R model), and lipopolysaccharide-induced toxemia (LPS model) mice. Samples were collected at 12 hours after reperfusion or administration. B: Survival rate of sham and mice injected with 50,75 , and $100 \mathrm{mg} / \mathrm{kg}$ of histones. C: Representative macroscopic images of lungs from control and histone-treated $(100 \mathrm{mg} / \mathrm{kg}, 10 \mathrm{mi}-$ nutes) mice. D: Serum analysis of tumor necrosis factor (Tnf)- $\alpha$, Il-1 $\beta$, Il- 6 , and Il-10 levels in control, sham, and histone-treated $(25,50$, and $75 \mathrm{mg} / \mathrm{kg})$ mice, at 4 hours after administration. Circulating nucleosomes and cytokines were quantitated by ELISA. Data are expressed as means \pm SEM. $n \geq 5$ for all groups. ${ }^{*} P<0.05,{ }^{* *} P<0.01$ versus sham mice.

functional changes in the lungs, liver, and kidneys of mice injected with 25 to $75 \mathrm{mg} / \mathrm{kg}$ of histones, at 4 hours after administration. Consistent with the macroscopic findings, extracellular histones induced lung congestion and edema associated with neutrophil infiltration in the alveolar capillaries (Figure 2A). Moreover, lung pathology was aggravated in a dose-dependent manner, as demonstrated by lung injury scoring, neutrophil infiltration, and in vivo pulmonary permeability assays (Figure 2B). Although the livers of histone-treated mice displayed no significant macroscopic changes, histological analysis in mice injected with $75 \mathrm{mg} / \mathrm{kg}$ of histones revealed widespread hepatocyte necrosis accompanied by a significant increase in neutrophil infiltration in the sinusoids and necrotic hepatocytes (Figure 2, C and D). In line with these morphological findings, serum aspartate transaminase and alanine transaminase levels were significantly elevated in mice injected with 50 to $75 \mathrm{mg} / \mathrm{kg}$ of histones, whereas those in mice injected with $25 \mathrm{mg} / \mathrm{kg}$ of histones were only slightly increased when compared to levels in sham mice (Figure 2D). In the kidney, proximal tubular cell necrosis, brush border loss, cast formation, and peritubular capillary neutrophil infiltration were found in mice injected with 50 to $75 \mathrm{mg} / \mathrm{kg}$ of histones, as demonstrated by histological acute tubular necrosis scoring and a densitometric analysis of neutrophil infiltration (Figure 2, E and F). Furthermore, serum analysis of creatinine and blood urea nitrogen concentrations showed a significant deterioration in renal function concurrent with the observed pathological changes (Figure 2F). Taken together, these results suggest that extracellular histones released into the blood are rapidly distributed throughout the body and induce multiple organ injury in a dose-dependent fashion, and that enhanced capillary endothelial permeability and neutrophil infiltration may play a role in the onset of organ failure.

\section{Lung, Liver, and Kidney Injury Induced by Extracellular Histones Display an Organ-Specific Time Course}

To further characterize the pathogenic mechanism of extracellular histones in multiple organ injury, we examined the chronological changes in the lungs, liver, and kidneys of mice after injection with $75 \mathrm{mg} / \mathrm{kg}$ of histones. As expected, severe pulmonary edema occurred immediately in all mice after injections and was accompanied by permeability disruptions and neutrophil infiltration (Figure 3, A and B). The immediate pulmonary impairment peaked at 1 hour after injection and subsided with time. Immunostaining with the proliferation marker Ki-67 confirmed a significant increase in epithelial and endothelial cell proliferation within the alveolar walls at 16 hours after injection (data not shown), indicating ongoing repair of the alveolar walls. ${ }^{31}$ Unlike the rapid deterioration observed in the lungs, hepatic injuries gradually progressed and peaked at 4 hours after injection (Figure 3, C and D). Necrotic hepatocytes showed cell 
swelling and bright eosinophilic cytoplasm, and neutrophils infiltrated into the necrotic tissue, from 1 hour after the onset of cell death in contrast to their immediate appearance in the lungs. Furthermore, renal injuries appeared in a delayed fashion and peaked at 16 hours after injection (Figure 3, E and F). Histological examinations revealed a few casts in the distal tubules at 1 hour after injection, and focal tubular necrosis with neutrophil infiltration at around 4 hours. More

A

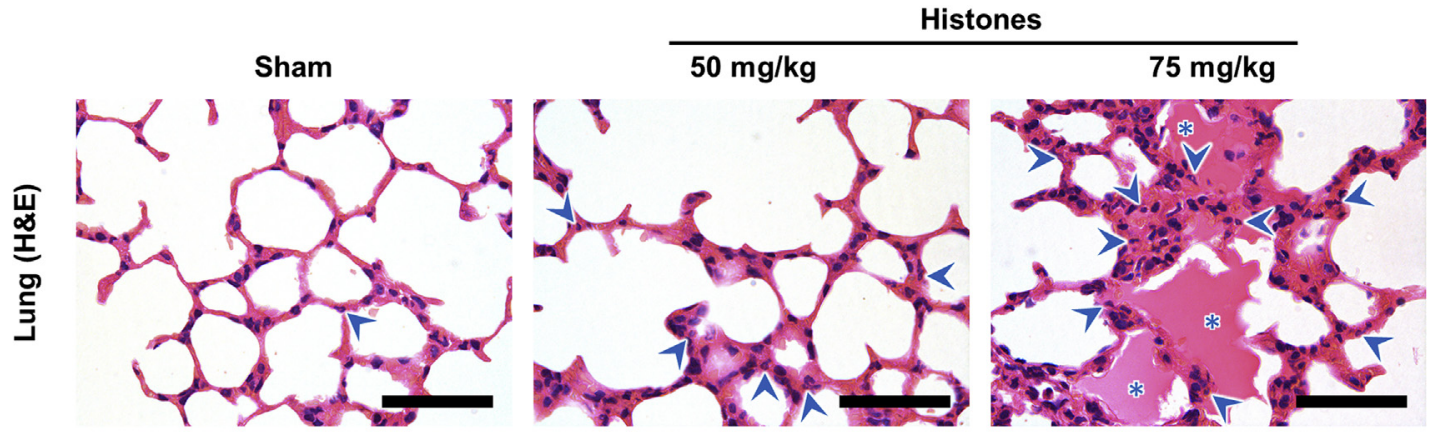

B

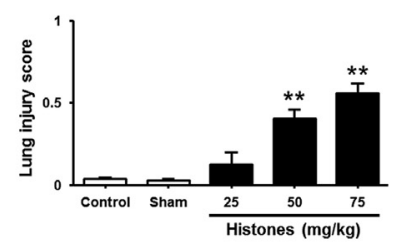

C
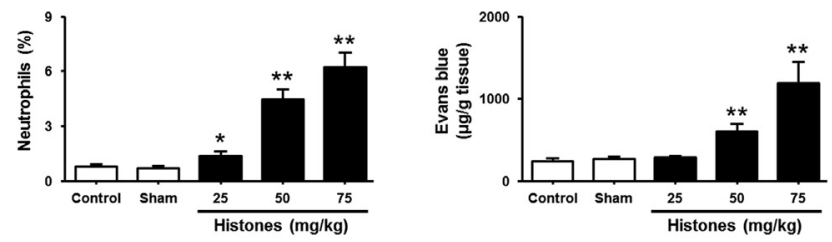

Histones
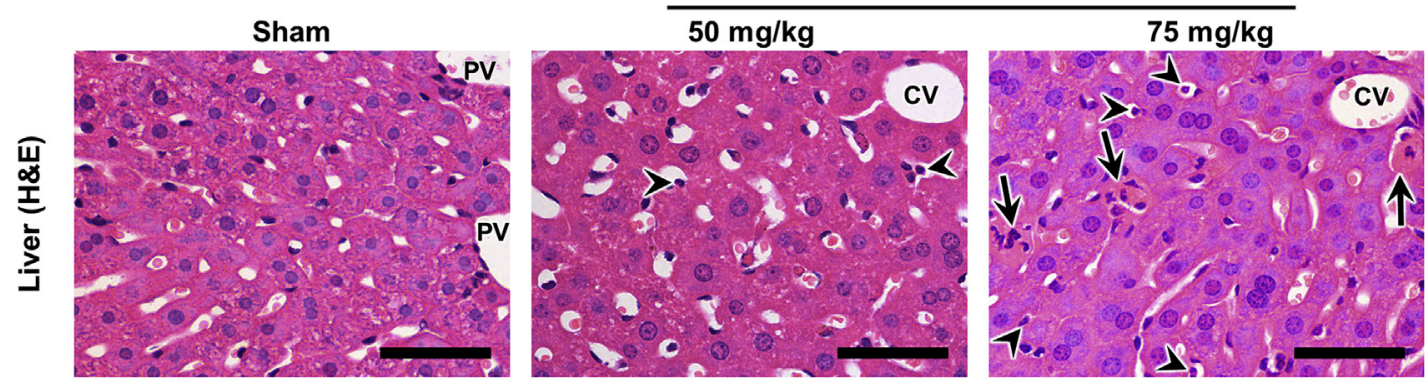

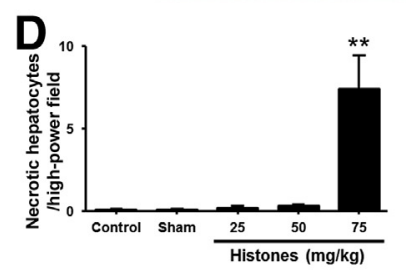

$\mathbf{E}$

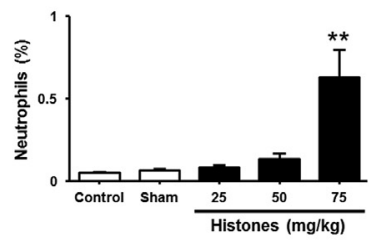

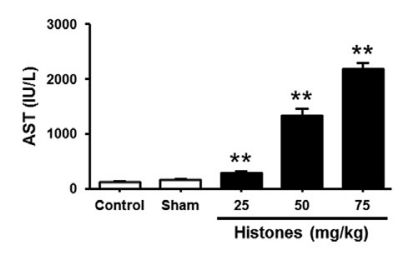

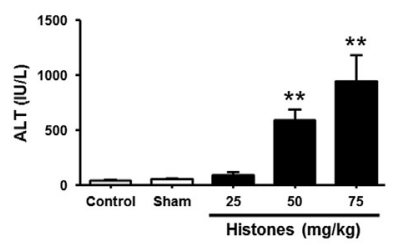

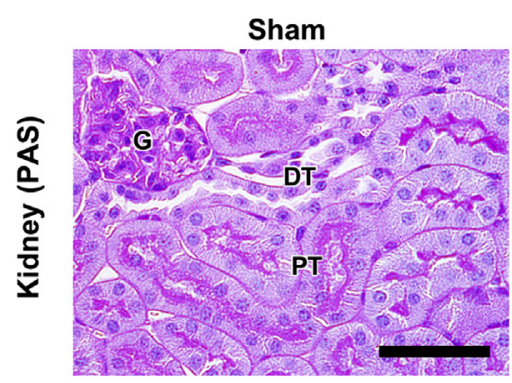
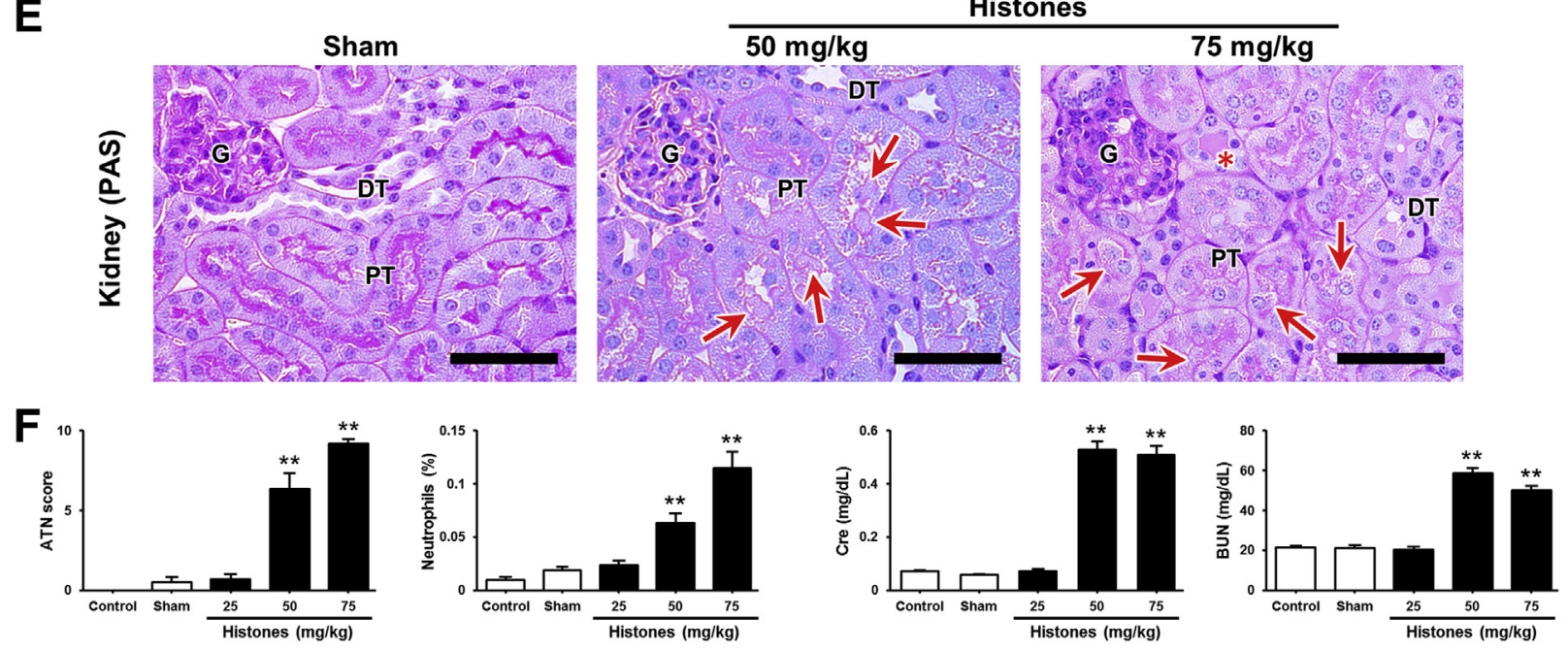
severe pathological findings developed at 16 hours after injection, characterized by massive tubular necrosis, detached epithelial cells, and prominent casts, which were not detected in control mice (Figure 3E). The necrotic tubular cells contained eosinophilic punctates in the cytoplasm, which were later identified as accumulations of damaged mitochondria by transmission electron microscopic analysis (Supplemental Figure S2). In addition, Ki-67 immunostaining revealed a significant increase in positive tubular cells at 64 hours after injection, indicating that tissue regeneration occurred after the injury peak at 16 hours (Supplemental Figure S3). These data suggest that histoneinduced injury manifestations, including the time course of injury onset, can vary across organs.

\section{Extracellular Histones Directly Damage Endothelial Cells, Leading to Multiple Organ Injury}

Because extracellular histone induced pulmonary edema associated with permeability defects and neutrophil infiltration in the capillaries, we hypothesized that extracellular histones directly affect endothelial cells and that the severity of the endothelial cell damage contributes to the progression of organ failure. To address these theories, we analyzed circulating soluble thrombomodulin - a marker of endothelial cell damage - in histone-injected mice. Notably, soluble thrombomodulin concentrations were significantly increased from 15 minutes to 4 hours after injection but subsided thereafter (Figure 4A), indicating that endothelial cell damage occurs rapidly and persists until 4 hours after injection. To determine whether extracellular histones directly disrupt endothelial cells, we analyzed the localization of histone $\mathrm{H} 3$ at 15 minutes after injection in formalin-fixed, paraffin-embedded and frozen tissue samples. These analyses demonstrated a linear deposition of histone $\mathrm{H} 3$ along the capillaries of the lungs and liver, but not the kidneys, in histone-treated mice (Figure 4, B and C). Furthermore, transmission electron microscopic analysis revealed that endothelial cell damage occurred at the same time point in the lungs and liver but not the kidneys (Figure 4D). In addition, mRNA expression of the endothelial injury marker Vegfr $2^{30}$ was also significantly increased only in the lungs and liver. Inflammatory cytokine mRNA expression was lesser in the lungs than in the liver and kidneys at 4 hours after injection (Figure 4E). These differences in cytokine levels were likely due to variations in inflammatory progression (Figure 3). Collectively, these data suggest that circulating extracellular histones directly damage endothelial cells in the lungs and liver, but not the kidneys, and closely associate with organ failure.

\section{Tlr2/4 mRNA Expression Increases after Endothelial Cell Injury}

Extracellular histones bind and activate TLRs (eg, TLR2/4) to induce innate immune responses that can lead to organ injuries. We hypothesized that TLR-related mechanisms may also play a role in the pathophysiology of histoneinduced injuries. ${ }^{14}$ To address this theory, we analyzed the mRNA expression levels of Tlr2 and Tlr4 at 15 minutes and 4 hours after injections compared to those in sham mice. Zymosan-a known TLR2 agonist-was also used for representing typical induced Tlr expression patterns. Both histones and zymosan failed to induce an increase in the mRNA expression of Tlr2 and Tlr4 at 15 minutes after injections, whereas the mRNA expression of Tlr 2 in the liver, and of Tlr 2 and Tlr4 in the kidney, was increased at 4 hours after histone injection (Figure 5A). Furthermore, we examined tissue injury in the lung, liver, and kidneys at 4 hours after the injection of histones and zymosan using Evans Blue, serum alanine transaminase, and creatinine levels, respectively (Figure 5B). Both histone and zymosan administration led to significant elevation of serum alanine transaminase and creatinine levels compared to those in sham mice. These findings suggest that TLR $2 / 4$ activation is likely involved in the pathophysiological mechanism underlying histone-induced organ injury, independent of the acute phase characterized by endothelial cell damage (Figure 4).

\section{Heparin Ameliorates Survival and Early Phase Histone-Induced Multiple Organ Injury}

Histones are known to have a strong positive charge that allows for binding to the negatively charged endothelial plasma membrane. ${ }^{17}$ As such, we hypothesized that i.v. administration of negatively charged molecules-such as heparin and albumin - might block this binding and attenuate histone-induced multiple organ injury. ${ }^{21,25}$ To address this hypothesis, we subjected histone-injected mice to

\footnotetext{
Figure 2 Extracellular histones induce multiple organ injury in a dose-dependent manner. Evaluation of lung, liver, and kidney injuries in control and sham mice and in those injected with 25,50 , and $75 \mathrm{mg} / \mathrm{kg}$ of histones, at 4 hours after administration. A and B: Histopathological and functional lung evaluation. A: Hematoxylin and eosin (H\&E) staining; arrowheads indicate neutrophil infiltration in alveolar capillaries; asterisks, proteinaceous exudate in airspaces (pulmonary edema). B: Histological lung injury score, densitometric assessment of neutrophil infiltration, and in vivo pulmonary microvascular permeability assay (measured by Evans Blue dye). C and D: Histopathological and functional liver evaluation. C: H\&E staining; arrowheads, neutrophil infiltration in the sinusoids; arrows, necrotic hepatocytes with neutrophil infiltration. D: Histological counts of necrotic hepatocytes, densitometric assessment of neutrophil infiltration, serum levels of aspartate transaminase (AST) and alanine transaminase (ALT). E and F: Histopathological and functional kidney evaluation. E: Periodic acid-Schiff (PAS) staining; arrows, proximal tubular cell necrosis; asterisks, cast formation. F, histological acute tubular necrosis (ATN) score, densitometric assessment of neutrophil infiltration, serum levels of creatinine (Cre), and blood urea nitrogen (BUN). Data are expressed as means \pm SEM. ${ }^{\star} P<0.05,{ }^{*} P<0.01$ versus sham mice. $n \geq 6$ for all groups. Scale bars $=50 \mu \mathrm{m}$. CV, central vein; DT, distal tubules; G, glomeruli; PT, proximal tubules; PV, portal vein.
} 
A

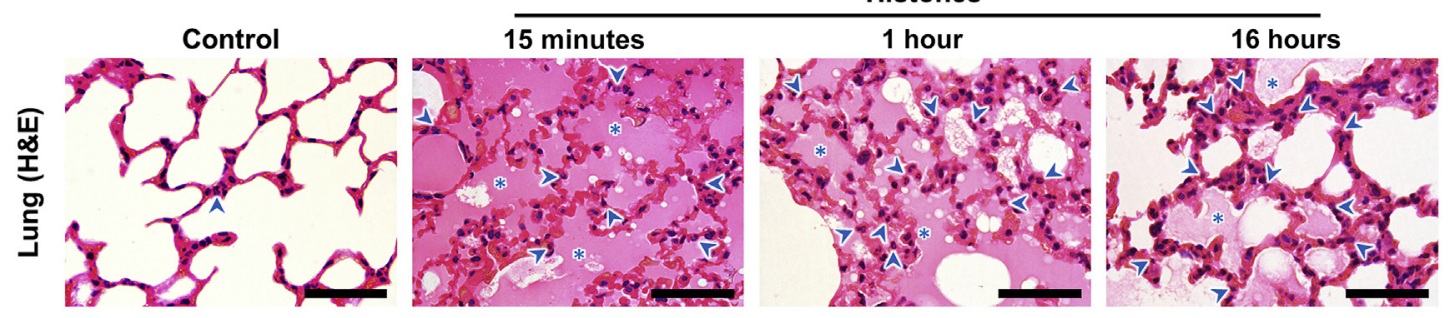

B
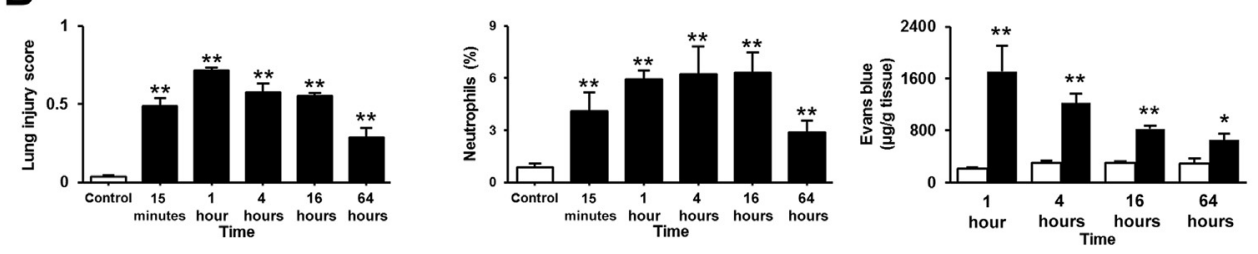

C
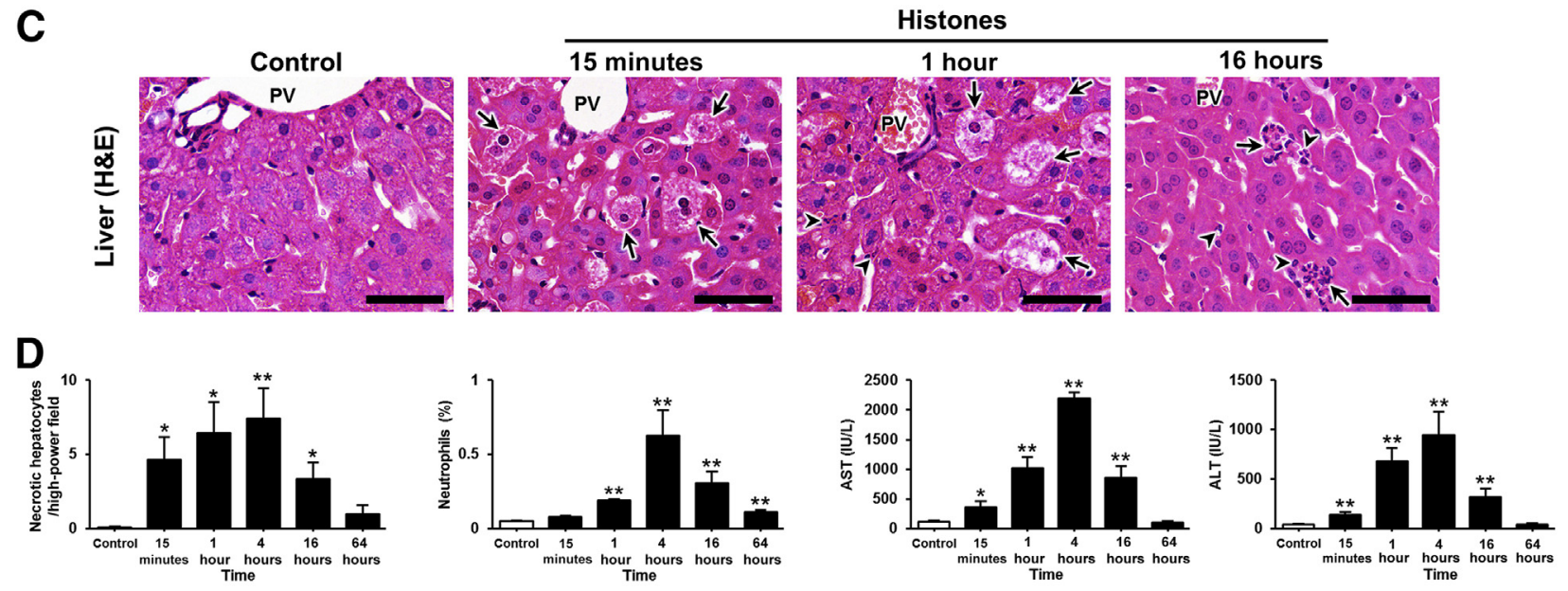

$\mathbf{E}$
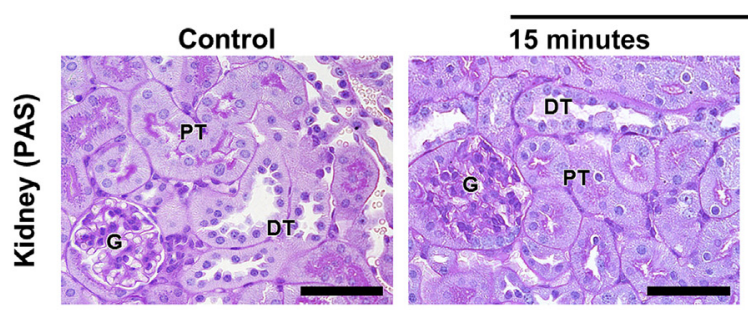

Histones
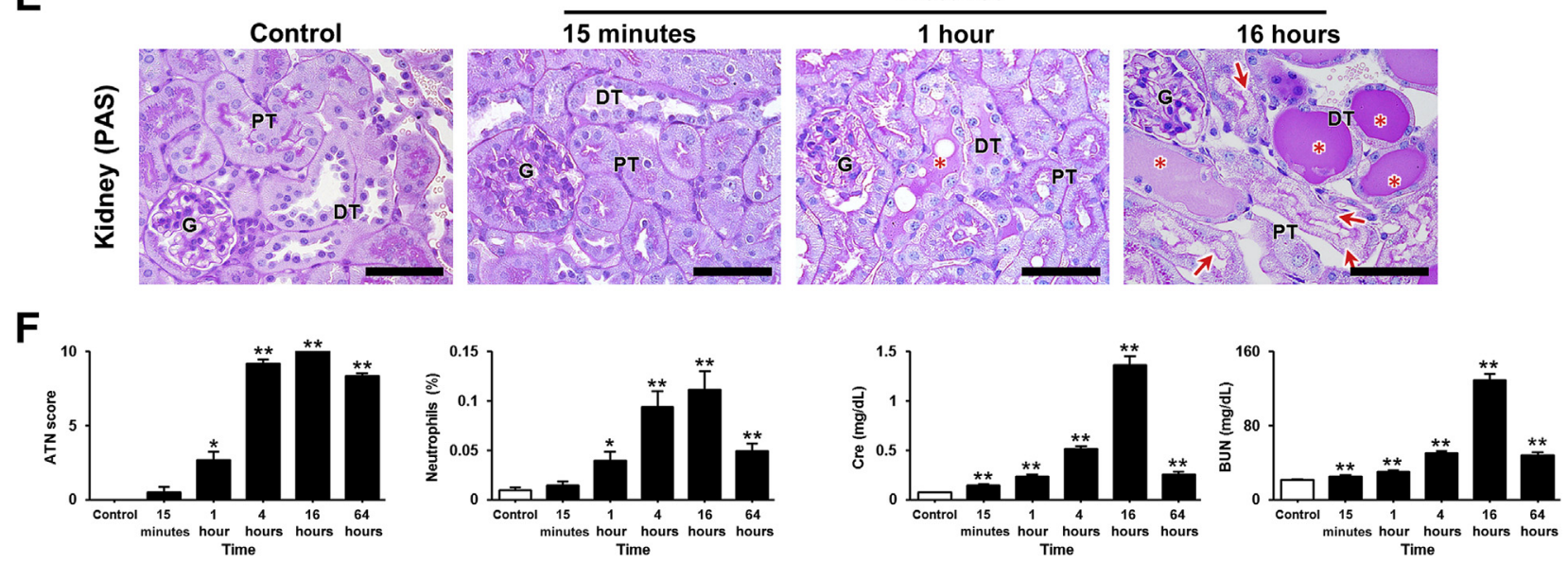

Figure 3 Lung, liver, and kidney injury induced by extracellular histones display an organ-specific time course. Evaluation of lung, liver, and kidney injuries in controls and in mice injected with $75 \mathrm{mg} / \mathrm{kg}$ of histones, at 15 minutes and 1, 4, 16, and 64 hours after administration. A and B: Histopathological and functional lung evaluations of control and histone-treated mice. A: Hematoxylin and eosin (H\&E) staining; arrowheads indicate neutrophil infiltration; asterisks, proteinaceous exudate in airspaces (pulmonary edema). B: Histological lung injury score, densitometric assessment of neutrophil infiltration, and in vivo pulmonary microvascular permeability assay (measured by Evans Blue dye). C and D: Histopathological and functional liver evaluation. C: H\&E staining; arrowheads, neutrophil infiltration in the sinusoids; arrows, necrotic hepatocytes with/without neutrophil infiltration. D: Histological counts of necrotic hepatocytes, densitometric assessment of neutrophil infiltration, and aspartate transaminase (AST) and alanine transaminase (ALT) serum levels. E and F: Histopathological and functional kidney evaluation. E: Periodic acid-Schiff (PAS) staining; arrows, proximal tubular cell necrosis; asterisks, cast formation. F: Histological acute tubular necrosis (ATN) score, densitometric assessment of neutrophil infiltration, serum levels of creatinine (Cre), and blood urea nitrogen (BUN). Data are expressed as means \pm SEM. $n \geq 6$ for all groups. ${ }^{\star} P<0.05,{ }^{*} P<0.01$ versus controls. Scale bars $=50 \mu \mathrm{m}$. G, glomeruli; DT, distal tubules; PT, proximal tubular cell; PV, portal vein. 
A

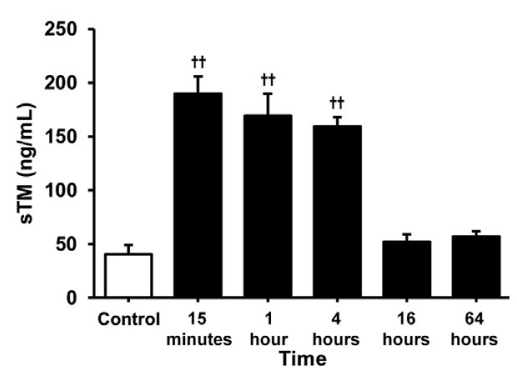

C

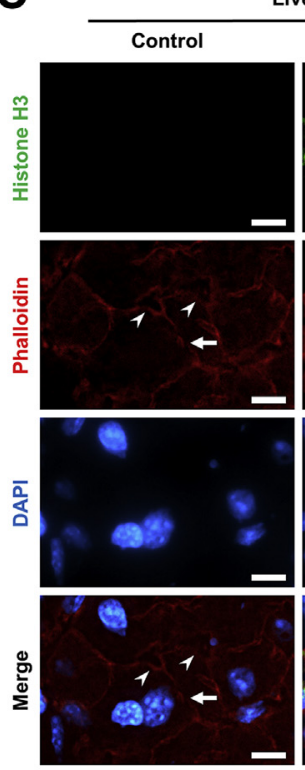

Liver
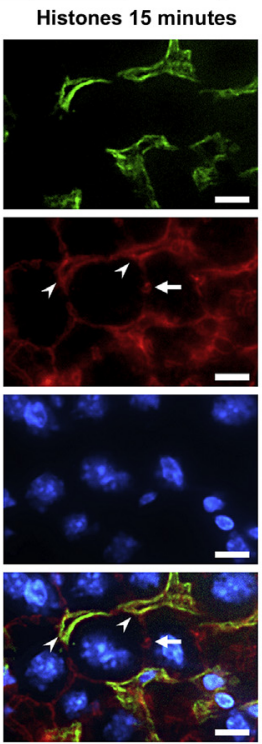

B

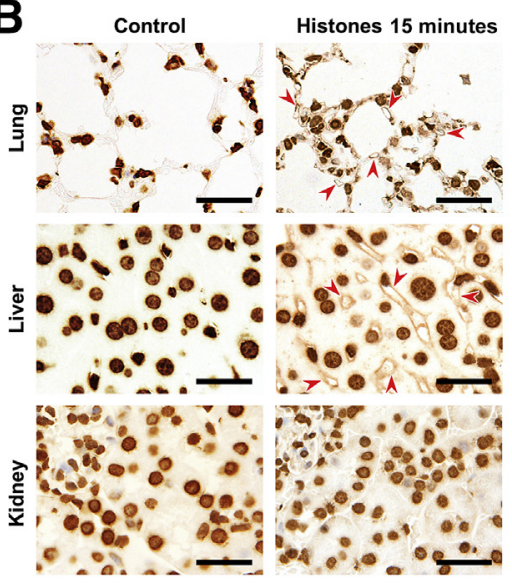

D
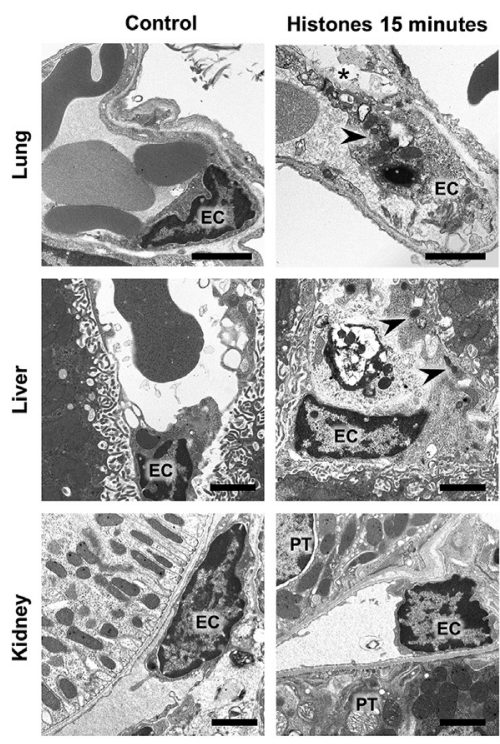
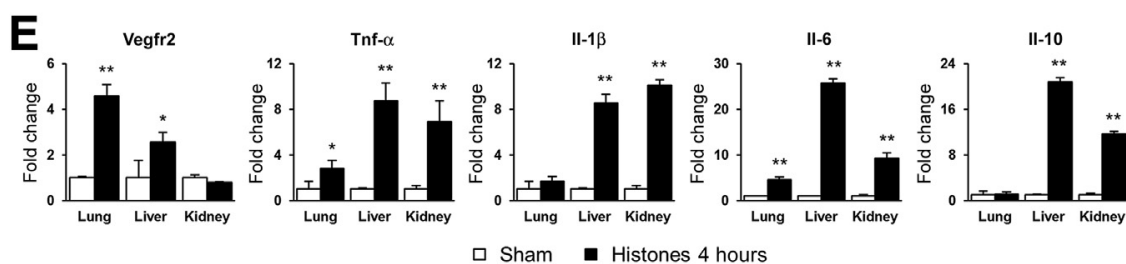

口 Sham Histones 4 hours

cotreatment with heparin or albumin. Notably, the survival of mice co-injected with heparin and histones was significantly greater than that in the albumin- or saline-treated counterparts (Figure 6A). Further, the survival of mice injected with heparin at 15 minutes after histone infusion - a more practical administration method for clinical scenarios-was also significantly greater than in the saline-treated counterparts $(P<0.05)$ (Supplemental Figure S4). To confirm that the enhanced survival of heparin-treated mice was due to the inhibition of histone adherence to endothelial cells, we performed histone $\mathrm{H} 3$ immunostaining and serum soluble thrombomodulin analysis. Consistent with the results of our survival study, heparin administration completely eradicated the linear deposition of histone $\mathrm{H} 3$ on liver sinusoids and

Figure 4 Extracellular histones directly damage endothelial cells, leading to multiple organ injury. A: Soluble thrombomodulin (sTM) serum levels in controls and in mice injected with $75 \mathrm{mg} / \mathrm{kg}$ of histones, at 15 minutes and 1, 4, 16, and 64 hours after administration. STM was quantitated by ELISA. B: Histone $\mathrm{H} 3$ immunostaining in lungs, liver, and kidneys from control and histone-treated $(75 \mathrm{mg} / \mathrm{kg}$, 15 minutes) mice. Arrowheads indicate positive capillary staining. C: Representative images of histone $\mathrm{H} 3$ immunofluorescence staining in the livers of control and histone-treated ( $75 \mathrm{mg} / \mathrm{kg}, 15$ minutes) mice. Green, histone H3; red, phalloidin; blue, DAPI; arrowheads, liver sinusoids; arrows, bile canaliculi. D: Transmission electron microscopy images of capillaries in lungs, livers, and kidneys from control and histone-treated $(75 \mathrm{mg} / \mathrm{kg}, 15$ minutes) mice. Arrowheads indicate necrotic endothelial cells with bright cytoplasm, swollen mitochondria, and loss of plasma membrane; asterisk, detachment of endothelial cell from basement membrane. E: Quantitative RT-PCR analysis in lungs, livers, and kidneys from sham and histone-treated $(75 \mathrm{mg} / \mathrm{kg})$ mice, at 4 hours after administration. Values were normalized to glyceraldehyde-3-phosphate dehydrogenase (Gapdh) expression. Data are expressed as means \pm SEM. $n \geq 6$ (A, all groups), $n \geq 3$ for (E, all groups). ${ }^{*} P<0.05,{ }^{* *} P<0.01$ versus sham mice. ${ }^{\dagger \dagger} P<0.01$ versus controls. Scale bars: $30 \mu \mathrm{m}$ (B), $10 \mu \mathrm{m}$ (C), $2 \mu \mathrm{m}$ (D). EC, endothelial cell; PT, proximal tubular cell; Tnf, tumor necrosis factor; Vegfr, vascular endothelial growth factor receptor.

protected endothelial cells from histone-mediated insults (Figure 6, B and C). Moreover, heparin-treated mice also showed a significant improvement in histological and functional analyses of lungs, liver, and kidneys (Figure 6, D-F, and Supplemental Figure S5). Contrary to initial expectations, the albumin-treated mice displayed a dense accumulation of histones along the liver sinusoids, which coincided with a marked deterioration in liver histological parameters and function (Figure 6, B and E, and Supplemental Figure S5). Thus, these findings suggest that the administration of i.v. heparin, but not albumin, can inhibit the toxic effects of extracellular histones by disrupting histone binding to endothelial cells and may have potential therapeutic benefits in multiple organ injury. 
A
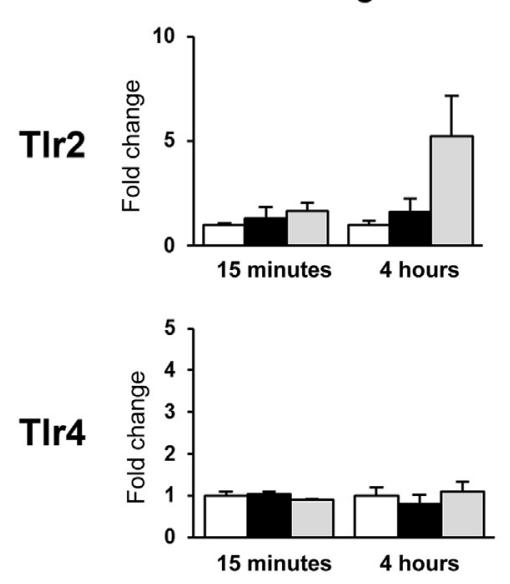

B

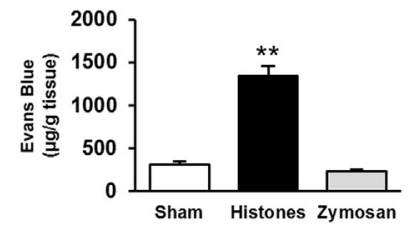

Liver
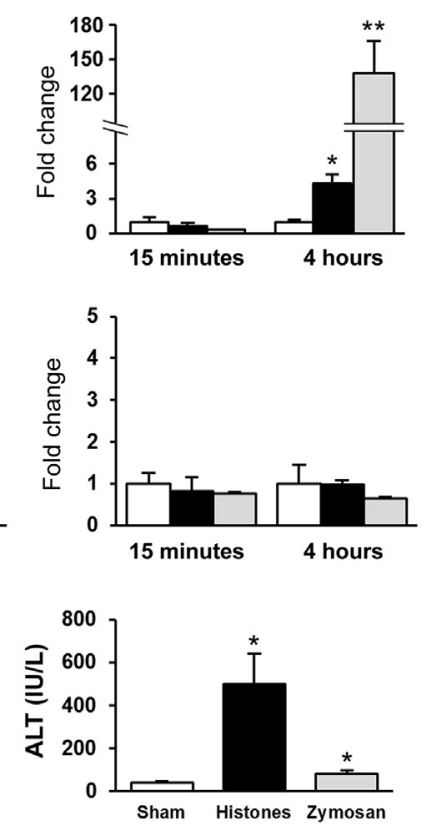

Kidney
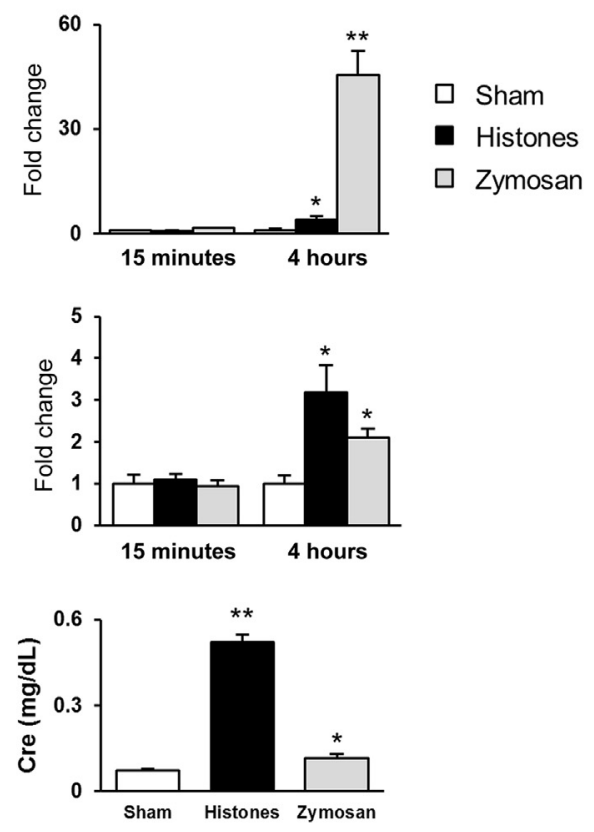

Figure 5 Toll-like receptor (TLR) 2/4 mRNA expression increases after endothelial cell injury. A: Tlr2 and Tlr4 mRNA expression in lungs, livers, and kidneys from sham mice and mice treated with $75 \mathrm{mg} / \mathrm{kg}$ of histones or zymosan, at 15 minutes and 4 hours after administration. Values were quantitated by RT-PCR and normalized to glyceraldehyde-3-phosphate dehydrogenase (Gapdh) expression. B: In vivo pulmonary microvascular permeability assay (measured by Evans Blue dye) and serum levels of alanine transaminase (ALT) and creatinine (Cre) in sham mice and mice injected with $75 \mathrm{mg} / \mathrm{kg}$ of histones or zymosan, at 4 hours after administration. Data are presented as means \pm SEM. $n \geq 3$ for all groups. ${ }^{\star} P<0.05,{ }^{*} P<0.01$ versus sham mice.

\section{Anti-HMGB1 Antibody Ameliorates Delayed Damage Subsequent to Histone-Induced Organ Injuries}

Because histone-induced kidney injuries appeared in a delayed fashion and were not closely associated with histone adherence to endothelial cells (Figure 3, E and F, and Figure 4B), we postulated that secondary injuries by other DAMPs may contribute to late-phase kidney injury. HMGB1 is a nonhistone nuclear protein that acts as a latephase mediator in DAMP-related pathogenesis. ${ }^{3,26}$ Evaluation of Hmgb1 in the mechanism of histone-induced organ injury by immunohistochemistry analysis revealed that it dissipated from the nuclei 1 hour after histone injection and partially relocalized at 16 hours after injection (Figure 7A). Furthermore, serum Hmgb1 levels in histone-treated mice were significantly elevated until 4 hours after injection, as shown by ELISA (Figure 7B). In addition, the administration of anti-Hmgb1 neutralizing antibody before and immediately after histone injection ameliorated histoneinduced multiple organ injury at 16 hours after histone injection, as shown by reduced serum alanine transaminase and creatinine levels, when compared to those in isotypetreated controls (Figure $7 \mathrm{C}$ ). Taken together, our results suggest that circulating extracellular histones initially cause organ injuries through a direct effect on endothelial cells, which triggers a subsequent translocation of HMGB1 from the nuclei that can induce secondary injuries in a delayed fashion. Thus, the combined targeting of histone and
HMGB1 may be a promising strategy for treating multiple organ injury.

\section{Discussion}

The present study shows that circulating extracellular histones act as a mediator within the pathogenic mechanism underlying multiple organ injury in mice (Figure 8). These circulating histones injured the lungs, liver, and kidneys in a dose-dependent fashion. Moreover, the degree and temporal onset of histone-induced injuries varied in an organ-specific manner, whereby pulmonary and hepatic injuries occurred immediately after histone administration through endothelial damage and renal injuries at a later phase of progression. Furthermore, extracellular histones triggered the release of Hmgb1 - another DAMP molecule-from injured tissues, resulting in a vicious cycle of multiple organ injury. In addition, this study revealed that heparin and anti-HMGB1 antibody are possible therapeutic agents for multiple organ injury. Specifically, heparin prevented extracellular histones from binding to endothelial cells, most likely by neutralizing the positive charge of the histones, thereby preventing the charge interaction with the endothelial plasma membrane. Alternatively, Hmgb1 antibody inhibited the effects of a secondary DAMP release during the late phase of injury, thereby blocking the vicious cycle. We believe that the role of extracellular histone cytotoxicity in multiple organ injury 


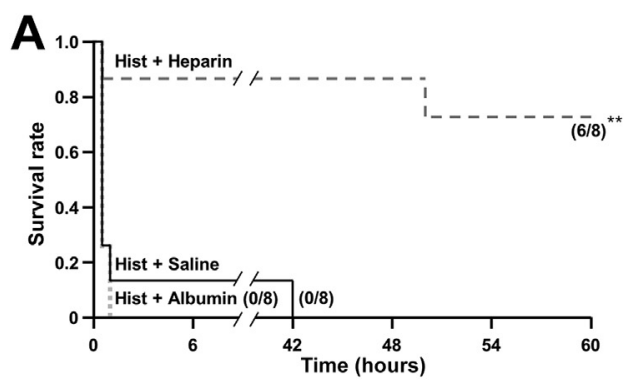

B
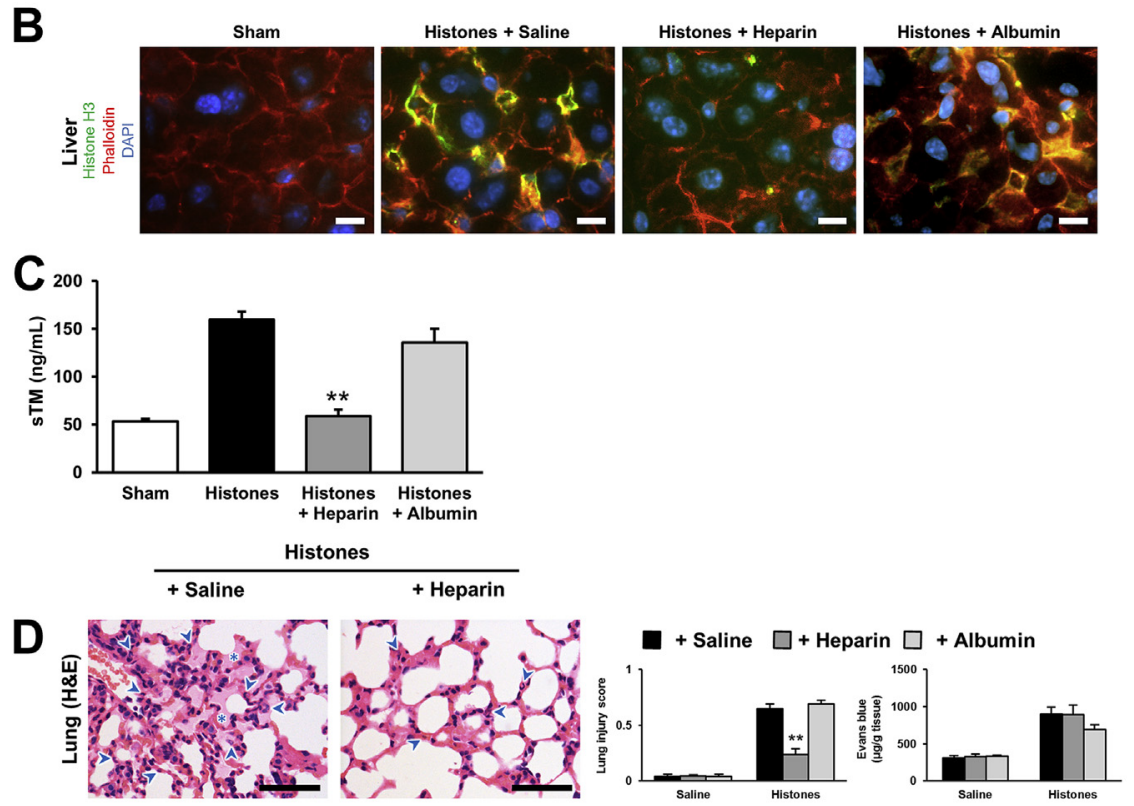

E
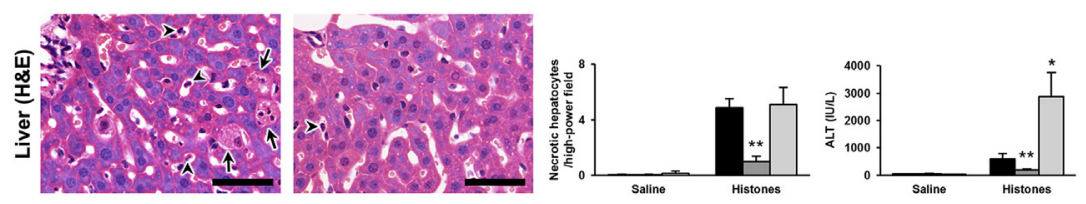

$\mathbf{F}$
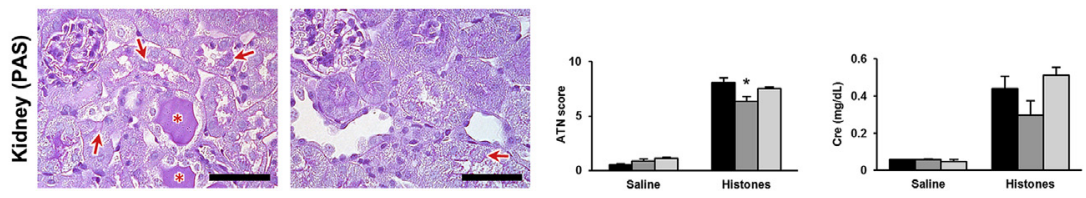

Figure 6 Heparin ameliorates survival and early phase histone-induced multiple organ injury. A: Survival rate of mice co-injected with $100 \mathrm{mg} / \mathrm{kg}$ histones (Hist) and saline, $10 \mathrm{mg} / \mathrm{kg}$ of heparin or $1 \mathrm{~g} / \mathrm{kg}$ of albumin. B: Representative images of histone $\mathrm{H} 3$ immunofluorescence staining in the livers of sham mice and mice treated or co-injected with $75 \mathrm{mg} / \mathrm{kg}$ of histones and saline, $10 \mathrm{mg} / \mathrm{kg}$ of heparin, or $1 \mathrm{~g} / \mathrm{kg}$ of albumin, at 15 minutes after administration. Green, histone H3; red, phalloidin; blue, DAPI. C: Serum soluble thrombomodulin (STM) levels in sham mice or in their counterparts co-injected with $75 \mathrm{mg} / \mathrm{kg}$ of histones and saline, $10 \mathrm{mg} / \mathrm{kg}$ of heparin, or $1 \mathrm{~g} / \mathrm{kg}$ of albumin, at 4 hours after administration. D-F: Evaluation of lung, liver, and kidney injuries in mice co-injected with 75 $\mathrm{mg} / \mathrm{kg}$ of histones and saline, $10 \mathrm{mg} / \mathrm{kg}$ of heparin, or $1 \mathrm{~g} / \mathrm{kg}$ of albumin, at 4 hours after administration. D: Histopathological and functional lung evaluation. Hematoxylin and eosin (H\&E) staining; arrowheads indicate neutrophil infiltration; asterisks, proteinaceous exudate in airspaces (pulmonary edema); histological lung injury score; in vivo pulmonary microvascular permeability assay. E: Histopathological and functional liver evaluation. H\&E staining; arrowheads, neutrophil infiltration; arrows, necrotic hepatocytes; histological counts of necrotic hepatocytes; alanine transaminase (ALT) serum levels. F: Histopathological and functional kidney evaluation. Periodic acid-Schiff (PAS) staining; arrows, proximal tubular cell necrosis; asterisks, cast formation; histological acute tubular necrosis (ATN) score; serum creatinine (Cre) levels. Data are expressed as means \pm SEM. $n \geq 6$ for all groups. ${ }^{*} P<0.05,{ }^{* *} P<0.01$ versus mice co-injected with histones and saline. Scale bars, $10 \mu \mathrm{m}$ (B), $50 \mu \mathrm{m}$ (D-F). and the potential therapeutic strategies described here provide new insight into research contributing to improving the prognosis of patients with MOF.

Histones are major nucleoproteins that pack DNA into nucleosomes and regulate gene expression. ${ }^{32}$ There are five major histone families, which are subcategorized into two groups-core histones (H2A, H2B, H3, and H4), which assemble to form one octameric nucleosome core, and a linker histone (H1). Histones, particularly $\mathrm{H} 3$ and $\mathrm{H} 4$, exhibit a substantial positive charge due to their high content of the basic amino acids (eg, lysine and arginine) necessary for their interaction with DNA. ${ }^{33}$ Thus, histones can bind directly to the negatively charged endothelial cell plasma membrane via their positive charge. ${ }^{16}$ The present study also showed this phenomenon in the results of histone H3immunohistochemistry analysis and a blocking assay for the histone-endothelium binding with negatively charged heparin (Figure 4, B and C, and Figure 6B). Moreover, this binding caused immediate destruction of endothelial cells, as shown in the results of serum soluble thrombomodulin measurement and transmission electron microscopic analysis (Figure 4, A and D). These findings are comparable to those from a previous in vitro study, in which calcium influx-induced cell death occurred immediately after the adherence of histones to cultured endothelial cells. ${ }^{9}$ These immediate effects of circulating histones on endothelial cells may provide an explanation for the developmental mechanisms of systemic shock occurring early in the course of diseases/traumas. Histone-induced clinical TLR activation is another possible mechanism of endothelial cell death, but it occurred 8 to 24 hours after stimulation in previous studies of DAMP-induced injury. ${ }^{34}$ 
A
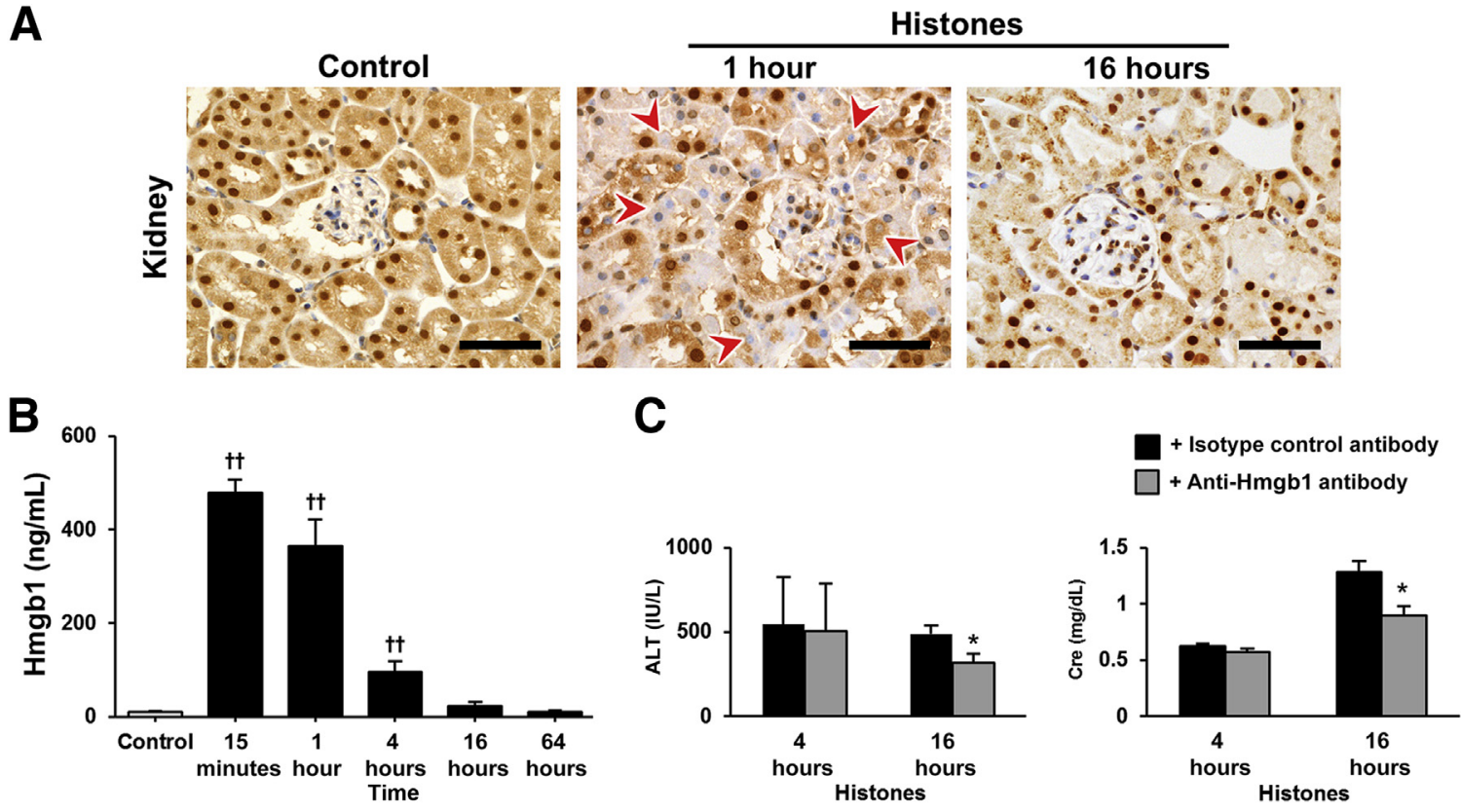

Figure 7 Anti-high-mobility group box 1 (Hmgb1) antibody ameliorates delayed damage subsequent to histone-induced organ injuries. A: Hmgb1 immunostaining in the kidneys of controls and mice injected i.v. with $75 \mathrm{~kg} / \mathrm{mg}$ of histones, at 1 and 16 hours after administration. Arrowheads indicate tubular epithelial cells with negative nuclei, indicative of Hmgb1 translocation to the cytoplasm or extracellular space. B: Serum levels of Hmgb1 in control mice and mice injected with $75 \mathrm{mg} / \mathrm{kg}$ of histone, at the indicated time points after administration. Serum levels of Hmgb1 were quantitated by ELISA. C: Alanine transaminase (ALT) and creatinine (Cre) serum levels in mice co-injected with histones and anti-Hmgb1 or isotype control antibody, at 4 and 16 hours after administration. Histones $(75 \mathrm{mg} / \mathrm{kg}$ ) were injected i.v., and anti-Hmgb1 antibody or isotype control antibody $(200 \mathrm{mg} / \mathrm{kg})$ were injected i.p. at 30 minutes before and at 1 hour after injection with histones. Data are expressed as means \pm SEM. $n \geq 5$ for all groups. ${ }^{\star} P<0.05$ versus histone/isotype control antibody injected mice; ${ }^{\dagger \dagger} P<0.01$ versus controls. Scale bars $=50 \mu \mathrm{m}$.

Circulating histones infused i.v. in mice appear to localize with an uneven distribution in various organs, with the lungs being particularly more susceptible than other organs. ${ }^{35}$ Recently, a study revealed that circulating-histone levels are also associated with cardiac injury in patients with sepsis $^{36}$; thus, the susceptibility of individual organs to histone toxicity is likely varied. Nonetheless, the mechanisms underlying this organ-specific susceptibility remain unclear. To better characterize the pathophysiology, our study examined the degree and time-dependency of tissue injury in response to histone injection in individual organs (Figures 2 and 3). Because histone-induced injuries were primarily the result of the direct binding to capillary endothelial cells, the physiological characteristics of capillaries within each organ may play an important role in the variability of susceptibility to tissue injury. Each organ has unique capillaries appropriate for its function. ${ }^{37}$ For instance, pulmonary microvascular endothelial cells display a strong anionic charge barrier necessary for maintaining the hydrodynamic balance and for preventing pulmonary edema. Conversely, this barrier charge also provides a binding site for positively charged histones. ${ }^{17}$ In fact, the present study illustrated that histones immediately adhered to pulmonary microvascular endothelial cells and caused severe pulmonary edema in a short time. In contrast, liver sinusoidal endothelial cells have prominent fenestrations, which permit the rapid passage of blood plasma to the space of Disse, ${ }^{30}$ allowing histones in the blood to come into direct contact with hepatocytes. This phenomenon may explain the simultaneous development of endothelial cell and hepatocyte necrosis in the present study. In the kidney, glomerular endothelial cells also have prominent fenestrations to produce urine from plasma, where small and/or positively charged proteins such as histones can easily pass from the blood circulation into the Bowman space and are subsequently excreted in the urine. ${ }^{38}$ Accordingly, our study found that histones were excreted in the urine of mice at 1 hour after histone injection (Supplemental Figure S6). Thus, the diversity of fenestration and charge character of the capillary endothelial cells in each organ may determine the extent of the susceptibility of that organ to histone-induced toxicity.

Because extracellular histones lead to a toxic reaction to endothelial cells through their positive charge, we speculated that negatively charged agents could attenuate histonemediated effects by neutralizing their positive charge. Both heparin and albumin are negatively charged agents and have been reported to attenuate the platelet-aggregation ability of histones. ${ }^{21,22}$ Consistently, we observed histone precipitation in the presence of heparin (Supplemental Figure S7). In addition, recent studies have revealed that i.p. or intratracheal heparin administration reduces mortality in rodent models of sepsis or acute lung injury ${ }^{21,39}$; i.v. heparin/histone co-injection also rescues mice administered a fatal dose 


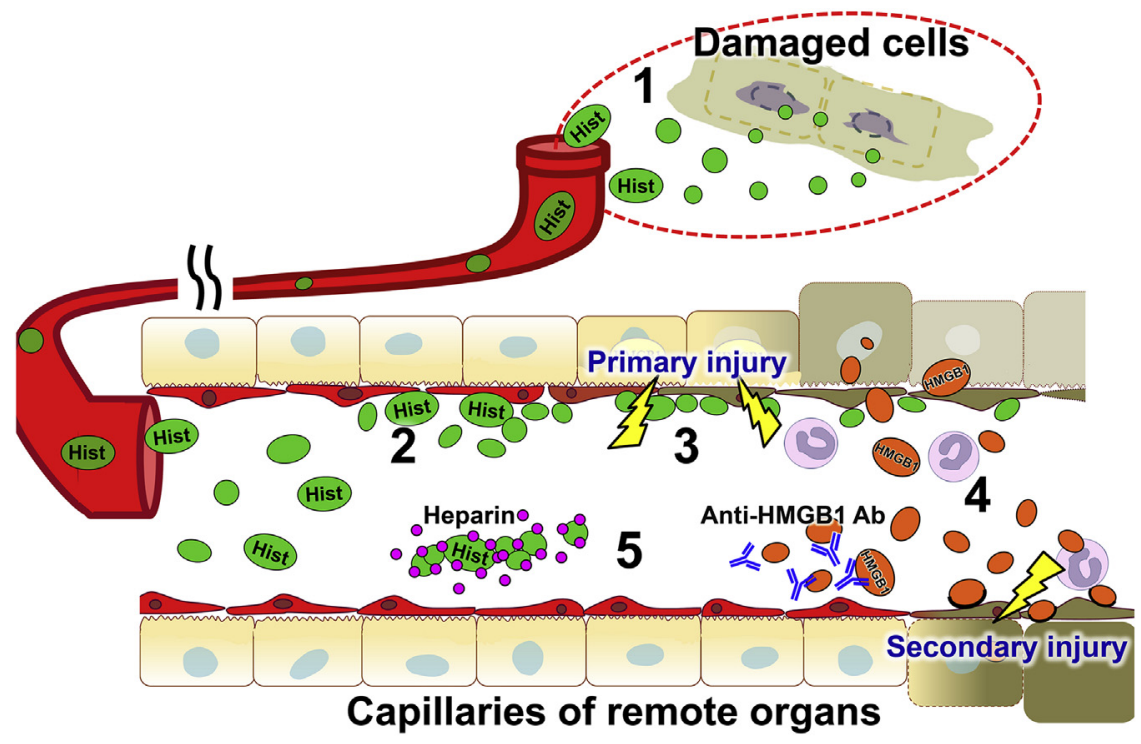

Figure 8 A proposed pathogenetic mechanism of circulating extracellular histone (Hist)-induced multiple organ injury and promising therapeutic strategies. (1) Histones released from damaged cells act as a damage-associated molecular pattern (DAMP) and are carried by the blood circulation to remote organs. (2) Circulating histones bind capillary endothelial cells in organ tissues through a charge interaction, and (3) result in the injury of endothelial cells and adjacent parenchymal cells (primary injury). (4) The injured cells subsequently release high-mobility group box 1 (HMGB1), causing further injury in contiguous tissues or other remote organs (secondary injury). Thus, extracellular histones elicit two progressive rounds of damage, resulting in multiple organ failure. (5) This phenomenon can be attenuated by treatment with heparin to block histone binding to endothelial cells, and anti-HMGB1 antibody (Ab) to abolish secondary injuries by neutralizing DAMP-mediated insults. of histones, ${ }^{25}$ similar to the findings observed in the present report. However, no in vivo study has elucidated whether heparin prevents circulating histones from binding to the endothelial cells. In the current study, we demonstrated that heparin improves multiple organ injuries and the survival rate of mice injected with a fatal dose of histones by inhibiting histone-endothelial cell binding (Figure 5). It should also be noted that heparin administration often induces defects in blood clotting ability; however, no complications were observed in our study. Taken together, the i.v. administration of heparin may be an effective therapy for MOF. Unexpectedly, albumin was devoid of therapeutic effects on histone toxicity. Instead, albumin administration appeared to aggravate liver injuries. It is well-known that edemas in critically ill patients may worsen after the administration of albumin. ${ }^{40,41}$ Nicholson et $\mathrm{al}^{41}$ explained the mechanism in their report: critically ill patients often have injured endothelial cells, and albumin administered to these patients easily leaks to the interstitium via the injured endothelial cells, resulting in interstitial edema and tissue damage. Thus, it is postulated that extracellular histones easily penetrate the injured endothelial cells with albumin and directly affect parenchymal cells. In fact, histones administrated with albumin densely accumulated in the liver sinusoids and induced hepatocyte necrosis (Figure 5B). The adverse effect of albumin administration shown in the present study, contrasting to a beneficial effect in previous in vitro analyses, ${ }^{22}$ emphasizes the careful choice and use of this agent in severely ill patients.

Circulating histones have been considered to be major mediators of sepsis-mediated damage in both humans and animal models, where plasma histone levels are positively correlated with disease severity. ${ }^{7,42}$ Infiltrating neutrophils, neutrophil extracellular traps, and massive cellular apoptosis/ necrosis are the primary sources of circulating histones. ${ }^{43}$ Moreover, histones have pro-coagulant effects, and patients with sepsis are often affected with coagulopathy, suggesting that histone-induced coagulopathy may play a role in the progression of sepsis and in ensuing MOF. ${ }^{25,42}$ Histones induce platelet activation via TLR2 and TLR4, transform prothrombin into thrombin by coagulation cascade activation, and cause fibrin formation by stimulating red blood cells. ${ }^{20,44}$ As such, these procoagulant effects may have been involved in the pathogenesis of multiple organ injury after histone injection in the present study. Although the anticoagulant effects of heparin could play a partial role in the improvement of multiple organ injury, recent studies have demonstrated that the beneficial effects of heparin in sepsis are independent of its anticoagulant properties. ${ }^{21,25}$ Furthermore, a randomized clinical trial failed to demonstrate a significant reduction in mortality in septic patients during the 28 days after the administration of unfractioned heparin. ${ }^{45}$ These studies suggest that heparin may have a distinct function in ameliorating histone-induced organ damage outside of its anticoagulant effects. Notably, our analyses revealed that this amelioration may occur by means of the differential charge present between heparin and histones, which may elicit beneficial effects in the immediate acute stage of injury. As such, we believe that further pharmacological studies of heparin administration-including the type of heparin, dosage, and optimal timing according to the stage of sepsis-are required for the improvement of patient survival. $^{46}$

Because a primary lesion in MOF is generally confined to a certain organ, it has been postulated that some biological factors may mediate a systemic response to progress to $\mathrm{MOF}^{5,6}$ The present study revealed that two DAMPs, histones and HMGB1, act in sequence to eventually induce multiple organ injury or death. Most previous studies have focused on the pathological mechanisms of certain DAMPs, ${ }^{4}$ and no study has elucidated that two or more DAMPs collaborate to induce 
multiple organ injury. Therefore, to our knowledge, this is the first in vivo study to reveal the enhancing mechanism of multiple organ injury progression by two different DAMPs. As the mediators probably play a pivotal role in inducing multiple organ injuries, agents inhibiting the mediator function can prevent the systemic spread of insults. In this study, we revealed that a neutralizing antibody targeting the secondary release of the HMGB1 was also a promising therapeutic agent in the late phase. Thus, this study provides new insight into MOF treatment strategies: treatment options vary depending on the MOF phase and/or targeting DAMP(s).

This in vivo study illustrates that histone injection leads to the release of HMGB1 from nuclei into the blood circulation; however, we did not investigate whether this release was a direct effect of histones. Future in vitro cell culture experiments may further elucidate this mechanism. Another limitation of the present study is that we did not fully evaluate the degree of TLR-related pathway involvement with respect to histone-induced organ injury; thus, studies to block the pathway using gene-knockout mice may clarify this issue.

In summary, the results obtained herein provide new insights into extracellular histone-related multiple organ injury pathogenesis and pharmacological treatment. Extracellular histones released after tissue trauma or diseases may lead to multiple organ injury and death. Histones elicit primary damage on endothelial cells via charge interaction, resulting in the release of DAMPs, which induce secondary tissue injuries. The susceptibility to histones varies among organs, likely depending on the unique characteristics of endothelial cells within each organ. Finally, we propose that histone and HMGB1 therapeutic blockades present a new strategy for treating histone-induced multiple organ injury.

\section{Acknowledgments}

We thank Hirozo Minami for technical assistance with the histological analyses, Haruyasu Kohda and Keiko Furuta for their technical assistance with electron microscopy, and the Center for Anatomical, Pathological and Forensic Research (Graduate School of Medicine, Kyoto University) for equipment support.

\section{Supplemental Data}

Supplemental material for this article can be found at http://dx.doi.org/10.1016/j.ajpath.2015.11.025.

\section{References}

1. Kono H, Rock KL: How dying cells alert the immune system to danger. Nat Rev Immunol 2008, 8:279-289
2. Tang D, Kang R, Coyne CB, Zeh HJ, Lotze MT: PAMPs and DAMPs: signal 0s that spur autophagy and immunity. Immunol Rev 2012, 249: $158-175$

3. Wang $\mathrm{H}$, Bloom $\mathrm{O}$, Zhang $\mathrm{M}$, Vishnubhakat JM, Ombrellino $\mathrm{M}$, Che J, Frazier A, Yang H, Ivanova S, Borovikova L, Manogue KR, Faist E, Abraham E, Andersson J, Andersson U, Molina PE, Abumrad NN, Sama A, Tracey KJ: HMG-1 as a late mediator of endotoxin lethality in mice. Science 1999, 285:248-251

4. Piccinini AM, Midwood KS: DAMPening inflammation by modulating TLR signalling. Mediators Inflamm 2010, 2010, Article ID 672395, doi:10.1155/2010/672395

5. Tsukamoto T, Chanthaphavong RS, Pape HC: Current theories on the pathophysiology of multiple organ failure after trauma. Injury 2010, $41: 21-26$

6. Osterbur K, Mann FA, Kuroki K, DeClue A: Multiple organ dysfunction syndrome in humans and animals. J Vet Intern Med 2014, 28:1141-1151

7. Xu J, Zhang X, Pelayo R, Monestier M, Ammollo CT, Semeraro F, Taylor FB, Esmon NL, Lupu F, Esmon CT: Extracellular histones are major mediators of death in sepsis. Nat Med 2009, 15: $1318-1321$

8. Huang H, Evankovich J, Yan W, Nace G, Zhang L, Ross M, Liao X, Billiar T, Xu J, Esmon CT, Tsung A: Endogenous histones function as alarmins in sterile inflammatory liver injury through Toll-like receptor 9 in mice. Hepatology 2011, 54:999-1008

9. Abrams ST, Zhang N, Manson J, Liu T, Dart C, Baluwa F, Wang SS, Brohi K, Kipar A, Yu W, Wang G, Toh CH: Circulating histones are mediators of trauma-associated lung injury. Am J Respir Crit Care Med 2013, 187:160-169

10. Borissoff JI, Joosen IA, Versteylen MO, Brill A, Fuchs TA, Savchenko AS, Gallant M, Martinod K, Ten Cate H, Hofstra L, Crijns HJ, Wagner DD, Kietselaer BL: Elevated levels of circulating DNA and chromatin are independently associated with severe coronary atherosclerosis and a prothrombotic state. Arterioscler Thromb Vasc Biol 2013, 33:2032-2040

11. Chen Q, Ye L, Jin Y, Zhang N, Lou T, Qiu Z, Jin Y, Cheng B, Fang $\mathrm{X}$ : Circulating nucleosomes as a predictor of sepsis and organ dysfunction in critically ill patients. Int J Infect Dis 2012, 16: e558-e564

12. Monach PA, Hueber W, Kessler B, Tomooka BH, BenBarak M, Simmons BP, Wright J, Thornhill TS, Monestier M, Ploegh H, Robinson WH, Mathis D, Benoist C: A broad screen for targets of immune complexes decorating arthritic joints highlights deposition of nucleosomes in rheumatoid arthritis. Proc Natl Acad Sci U S A 2009, 106:15867-15872

13. Allam R, Kumar SV, Darisipudi MN, Anders HJ: Extracellular histones in tissue injury and inflammation. J Mol Med (Berl) 2014, 92 465-472

14. Allam R, Scherbaum CR, Darisipudi MN, Mulay SR, Hagele H, Lichtnekert J, Hagemann JH, Rupanagudi KV, Ryu M, Schwarzenberger C, Hohenstein B, Hugo C, Uhl B, Reichel CA, Krombach F, Monestier M, Liapis H, Moreth K, Schaefer L, Anders HJ: Histones from dying renal cells aggravate kidney injury via TLR2 and TLR4. J Am Soc Nephrol 2012, 23: $1375-1388$

15. Semeraro F, Ammollo CT, Morrissey JH, Dale GL, Friese P Esmon NL, Esmon CT: Extracellular histones promote thrombin generation through platelet-dependent mechanisms: involvement of platelet TLR2 and TLR4. Blood 2011, 118:1952-1961

16. Gillrie MR, Lee K, Gowda DC, Davis SP, Monestier M, Cui L, Hien TT, Day NP, Ho M: Plasmodium falciparum histones induce endothelial proinflammatory response and barrier dysfunction. Am J Pathol 2012, 180:1028-1039

17. Freeman CG, Parish CR, Knox KJ, Blackmore JL, Lobov SA, King DW, Senden TJ, Stephens RW: The accumulation of circulating histones on heparan sulphate in the capillary glycocalyx of the lungs. Biomaterials 2013, 34:5670-5676 
18. Grailer JJ, Canning BA, Kalbitz M, Haggadone MD, Dhond RM, Andjelkovic AV, Zetoune FS, Ward PA: Critical role for the NLRP3 inflammasome during acute lung injury. J Immunol 2014, 192: $5974-5983$

19. Semeraro N, Ammollo CT, Semeraro F, Colucci M: Coagulopathy of Acute Sepsis. Semin Thromb Hemost 2015, 41:650-658

20. Gould TJ, Lysov Z, Liaw PC: Extracellular DNA and histones: doubleedged swords in immunothrombosis. J Thromb Haemost 2015, 13(Suppl 1):S82-S91

21. Wildhagen KC, Garcia de Frutos P, Reutelingsperger CP, Schrijver R, Areste C, Ortega-Gomez A, Deckers NM, Hemker HC, Soehnlein O, Nicolaes GA: Nonanticoagulant heparin prevents histone-mediated cytotoxicity in vitro and improves survival in sepsis. Blood 2014, 123:1098-1101

22. Lam FW, Cruz MA, Leung HC, Parikh KS, Smith CW, Rumbaut RE: Histone induced platelet aggregation is inhibited by normal albumin. Thromb Res 2013, 132:69-76

23. Daigo K, Nakakido M, Ohashi R, Fukuda R, Matsubara K, Minami T, Yamaguchi N, Inoue K, Jiang S, Naito M, Tsumoto K, Hamakubo T: Protective effect of the long pentraxin PTX3 against histone-mediated endothelial cell cytotoxicity in sepsis. Sci Signal 2014, 7:ra88

24. Abrams ST, Zhang N, Dart C, Wang SS, Thachil J, Guan Y, Wang G, Toh CH: Human CRP defends against the toxicity of circulating histones. J Immunol 2013, 191:2495-2502

25. Wang F, Zhang N, Li B, Liu L, Ding L, Wang Y, Zhu Y, Mo X, Cao Q: Heparin defends against the toxicity of circulating histones in sepsis. Front Biosci (Landmark Ed) 2015, 20:1259-1270

26. Kim JY, Park JS, Strassheim D, Douglas I, Diaz del Valle F, Asehnoune K, Mitra S, Kwak SH, Yamada S, Maruyama I, Ishizaka A, Abraham E: HMGB1 contributes to the development of acute lung injury after hemorrhage. Am J Physiol Lung Cell Mol Physiol 2005, 288:L958-L965

27. Sawyer RT: Intravenous zymosan-A challenge induces an alveolar inflammatory response. Inflammation 1993, 17:273-281

28. Moriuchi H, Arai I, Yuizono T: Tranexamic acid attenuates oleic-acidinduced pulmonary extravasation. Intensive Care Med 1995, 21: 1003-1008

29. Matute-Bello G, Downey G, Moore BB, Groshong SD, Matthay MA, Slutsky AS, Kuebler WM: An official American Thoracic Society workshop report: features and measurements of experimental acute lung injury in animals. Am J Respir Cell Mol Biol 2011, 44:725-738

30. Miyao M, Kotani H, Ishida T, Kawai C, Manabe S, Abiru H, Tamaki K: Pivotal role of liver sinusoidal endothelial cells in NAFLD/NASH progression. Lab Invest 2015, 95:1130-1144
31. Herold S, Gabrielli NM, Vadasz I: Novel concepts of acute lung injury and alveolar-capillary barrier dysfunction. Am J Physiol Lung Cell Mol Physiol 2013, 305:L665-L681

32. Andrews AJ, Luger K: Nucleosome structure(s) and stability: variations on a theme. Annu Rev Biophys 2011, 40:99-117

33. Von Holt C, Strickland WN, Brandt WF, Strickland MS: More histone structures. FEBS Lett 1979, 100:201-218

34. Wang H, Yang H, Czura CJ, Sama AE, Tracey KJ: HMGB1 as a late mediator of lethal systemic inflammation. Am J Respir Crit Care Med 2001, 164:1768-1773

35. Fattahi F, Grailer JJ, Jajou L, Zetoune FS, Andjelkovic AV, Ward PA: Organ distribution of histones after intravenous infusion of FITC histones or after sepsis. Immunol Res 2015, 61:177-186

36. Alhamdi Y, Abrams ST, Cheng Z, Jing S, Su D, Liu Z, Lane S, Welters I, Wang G, Toh CH: Circulating Histones Are Major Mediators of Cardiac Injury in Patients With Sepsis. Crit Care Med 2015, 43:2094-2103

37. Gallagher PJ: Blood Vessels. Edited by Mills SJ. Histology for Pathologists. ed 4. Philadelphia, PA, Lippincott Williams \& Wilkins, 2012, pp 233-258

38. Scott RP, Quaggin SE: Review series: the cell biology of renal filtration. J Cell Biol 2015, 209:199-210

39. Zhang Y, Zhao Z, Guan L, Mao L, Li S, Guan X, Chen M, Guo L, Ding L, Cong C, Wen T, Zhao J: N-acetyl-heparin attenuates acute lung injury caused by acid aspiration mainly by antagonizing histones in mice. PLoS One 2014, 9:e97074

40. Cochrane Injuries Group Albumin Reviewers: Human albumin administration in critically ill patients: systematic review of randomised controlled trials. BMJ 1998, 317:235-240

41. Nicholson JP, Wolmarans MR, Park GR: The role of albumin in critical illness. Br J Anaesth 2000, 85:599-610

42. Ekaney ML, Otto GP, Sossdorf M, Sponholz C, Boehringer M, Loesche W, Rittirsch D, Wilharm A, Kurzai O, Bauer M, Claus RA: Impact of plasma histones in human sepsis and their contribution to cellular injury and inflammation. Crit Care 2014, 18:543

43. Chaput C, Zychlinsky A: Sepsis: the dark side of histones. Nat Med 2009, 15:1245-1246

44. Yang X, Li L, Liu J, Lv B, Chen F: Extracellular histones induce tissue factor expression in vascular endothelial cells via TLR and activation of NF-kappaB and AP-1. Thromb Res 2015, 137:211-218

45. Jaimes F, De La Rosa G, Morales C, Fortich F, Arango C, Aguirre D, Munoz A: Unfractioned heparin for treatment of sepsis: a randomized clinical trial (The HETRASE Study). Crit Care Med 2009, 37: 1185-1196

46. Buras JA, Holzmann B, Sitkovsky M: Animal models of sepsis: setting the stage. Nat Rev Drug Discov 2005, 4:854-865 